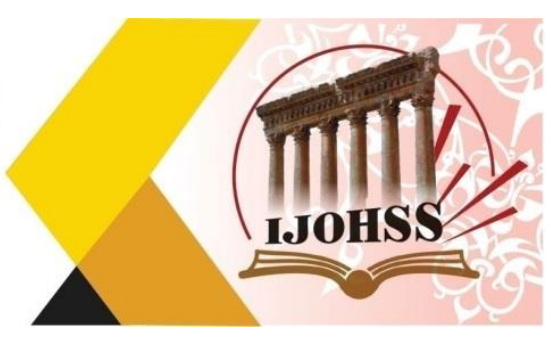

\title{
اللسانيــات التعليمية: دراسة في المفهوم والتصورات
}

\author{
الاستاذ المساعد الاكتور

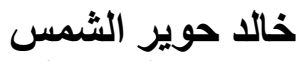 \\ قسم اللغة العربية \\ كلية التربية للعلوم الإنسانية - . جامعة ذي قار \\ العراق الإنة
}

البريد الاككتروني: Khalidhower@utq.edu.iq

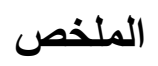

اللسانيات التعليمية حقل بيني، يشتغل على التمازج المعرفي بين علمي اللغة، والتربية، وله تسميات كثر: علم

اللغة التعليمي، التعليمية، التعليميات، اللسانيات التربوية، وله مفاهيم كثيرة، يجمع بين البنيوي، و التواصلي، و التعليم بالكفايات من أهم مقو لاته، تستلزم هذه المفاهيم الإيضاح، والتبيين، و التعريف؛ لانه ماز ال علما بكر ا في

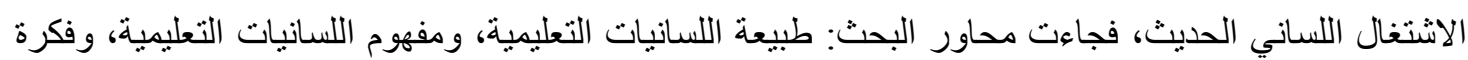
اللسانيات التعليمية، وبدايات اللسانيات التعليمية، ومرتكزات اللسانيات التعليمية، و اتجاهات اللسانيات التعليمية، ومبادئ اللسانيات التعليمية، وتجليات البينية في اللسانيات التعليمة. بحسب هذه المحاور صار هدف البحث: التعريف بها، ووضع تصور عنها، ثم رصد نقاط البينية بينها وبين علم التربية.

الكلمات المفتاحية: تعليمية، لسانيات تعليمية، الكفايات، بينية، ديداكتيك، علم اللغة التطبيقي. 


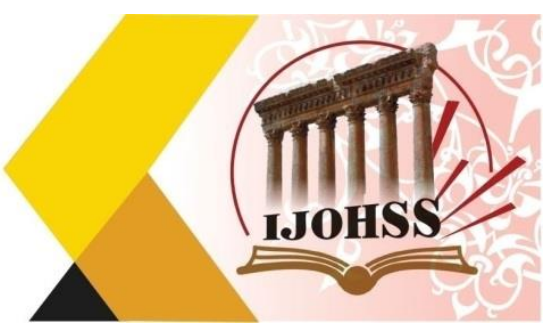

\title{
Educational Linguistics: A study in Concept and Perceptions
}

\author{
Assistant Professor \\ Dr. Khaled Huwer Al Shams \\ Department of Arabic Language \\ College of Education for Human Sciences - University of Thi-Qar \\ Iraq \\ Email: Khalidhower@utq.edu.iq
}

\begin{abstract}
Educational linguistics is an interdisciplinary field that works on the cognitive blending between linguistics and education. It has many names: educational linguistics, educational, instructional, educational linguistics. It has many concepts, combining structural, communicative, and competency education among its most important categories. These concepts require clarification. , illustrating, defining; Because it is still a virgin science in modern linguistic work, the research axes came: the nature of educational linguistics, the concept of educational linguistics, the idea of educational linguistics, the beginnings of educational linguistics, the foundations of educational linguistics, trends in educational linguistics, principles of educational linguistics, and the manifestations of the interface in educational linguistics. According to these themes, the aim of the research became: introducing it, developing a conception of it, and then monitoring the interface points between it and pedagogy.
\end{abstract}

Keywords: educational, didactic linguistics, competencies, interface, didactics, applied linguistics. 


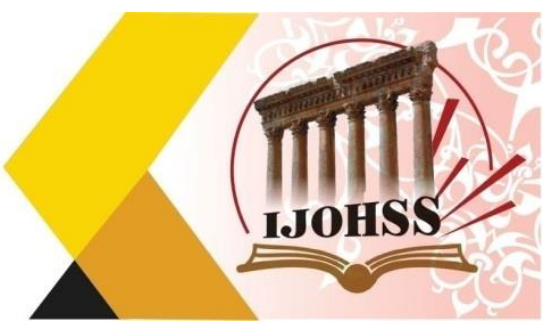

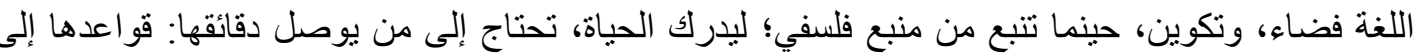

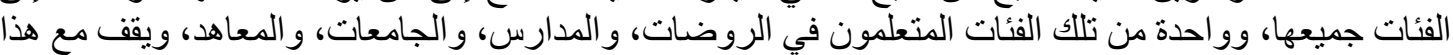

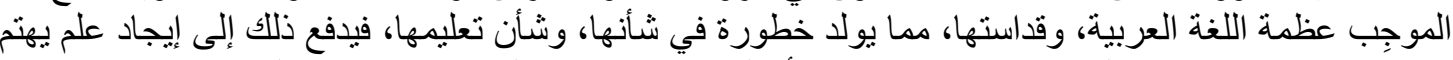

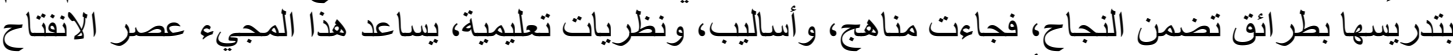

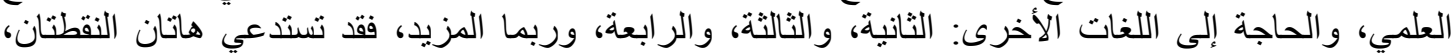

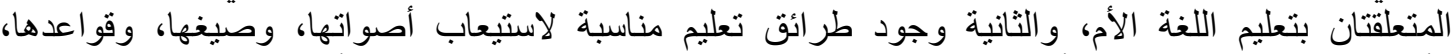

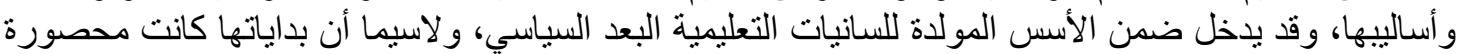

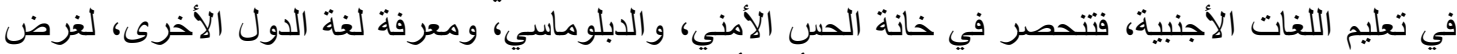

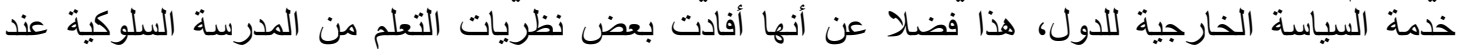

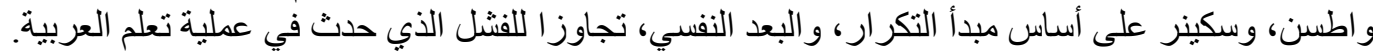

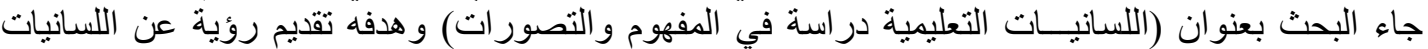

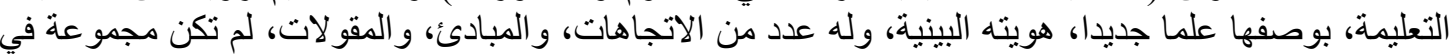

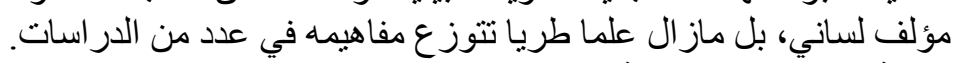

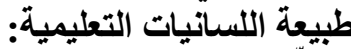

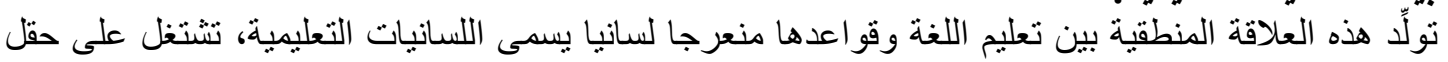

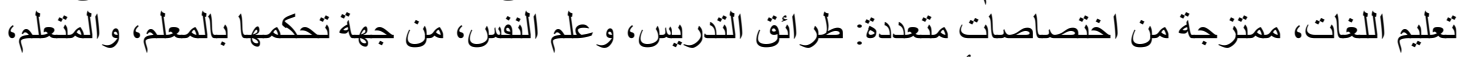

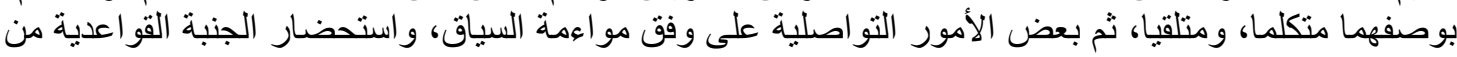

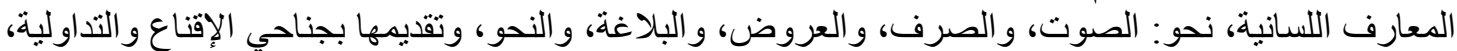

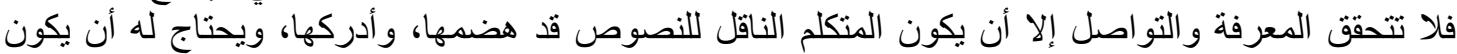

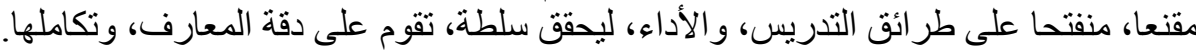

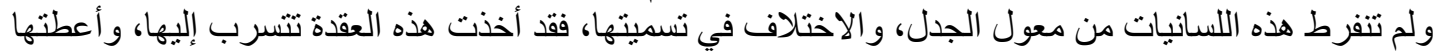

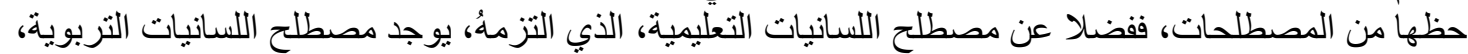

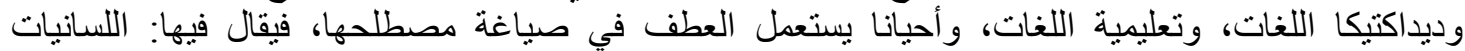

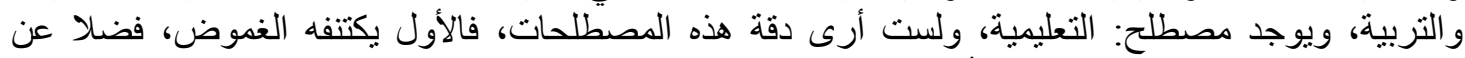

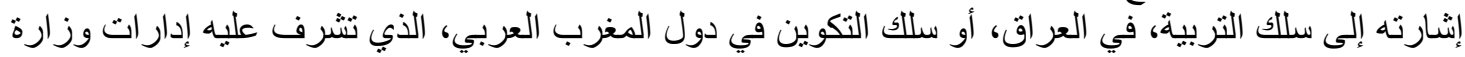

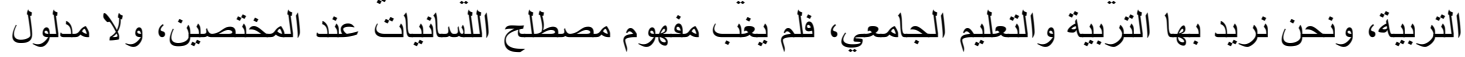

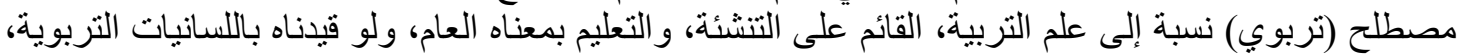
لدل على تعليم اللغات في طور التربية.

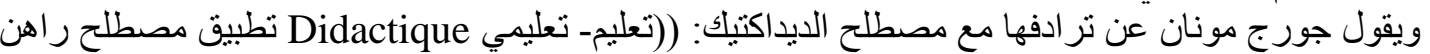

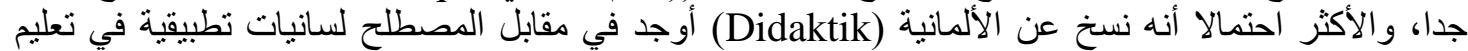

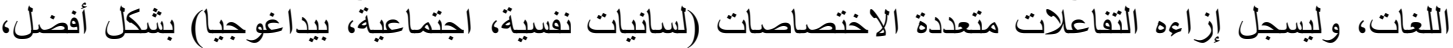

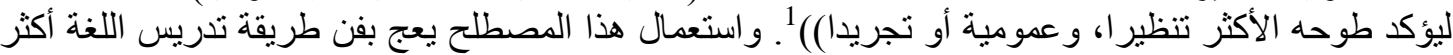

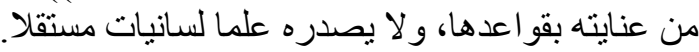

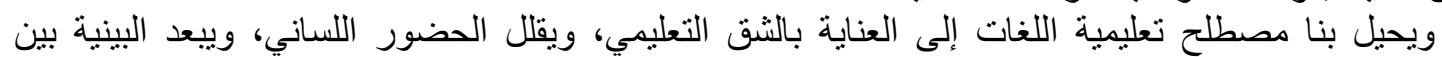
اللسانيات و النزربية.

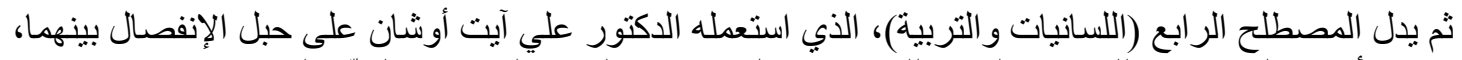

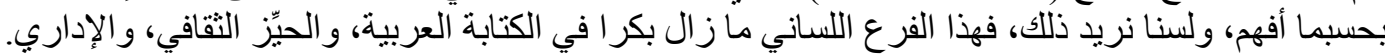

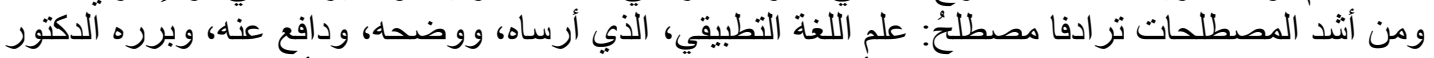

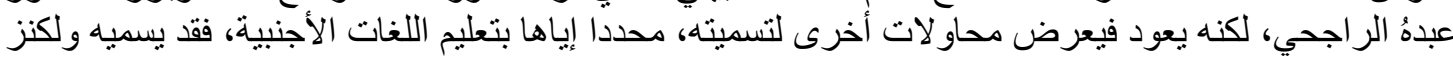

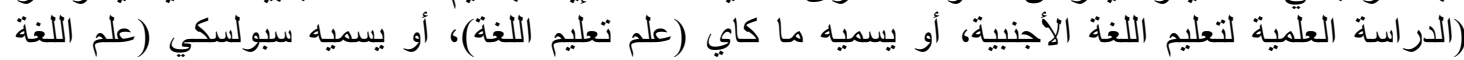

1 1 - معجم اللسانيات، بإنشر اف جورج مونان،: 144. 


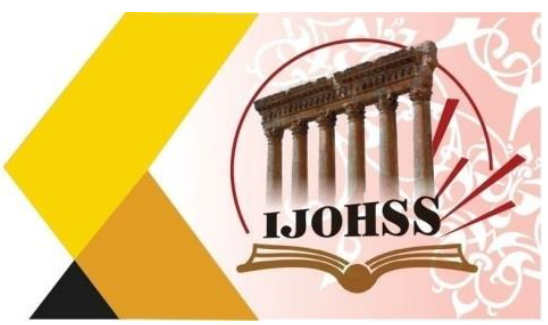

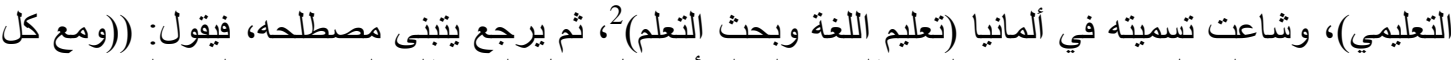

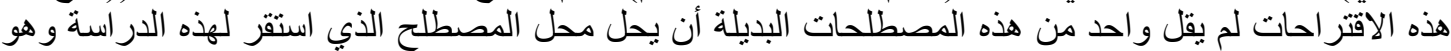

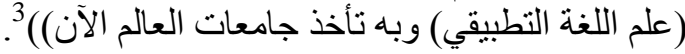

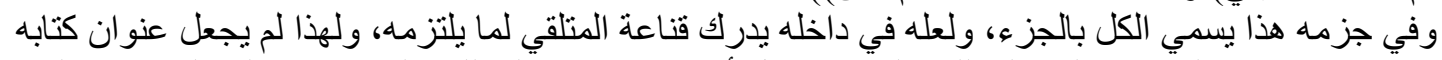

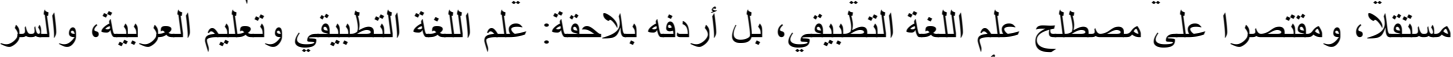

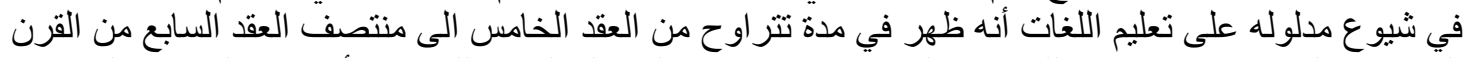

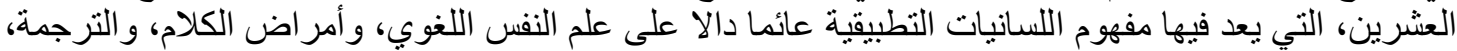

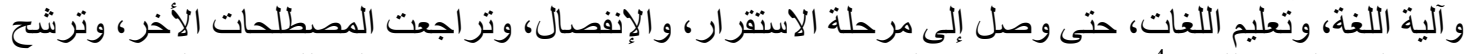

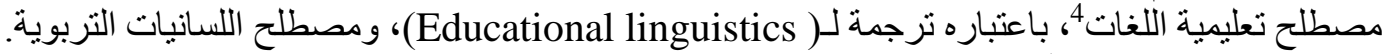

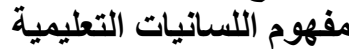
وفيما يخص مفهومها، فقد ظهر عدد من المفاهيم للسانيات التربوية على وفق معيار التداخل مع اللسانيات

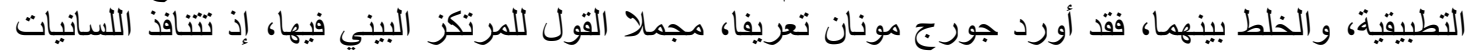

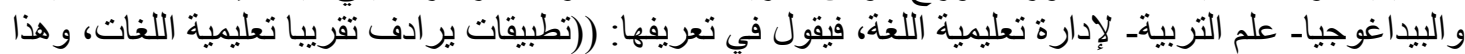

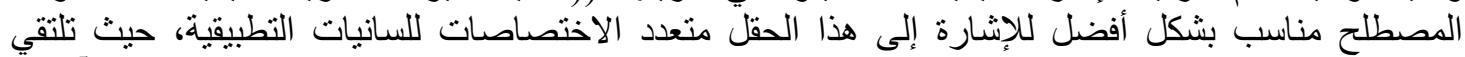

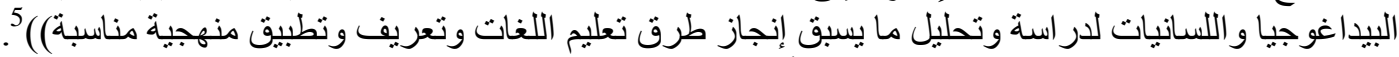

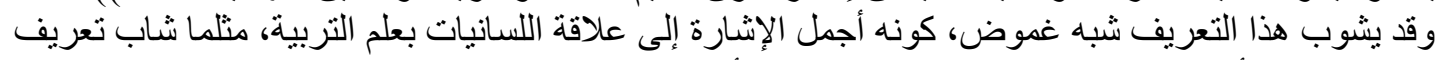

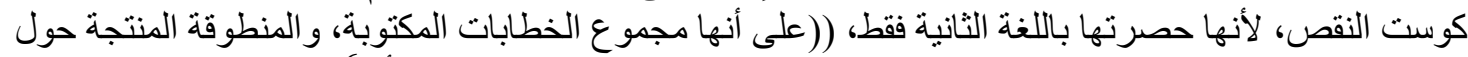

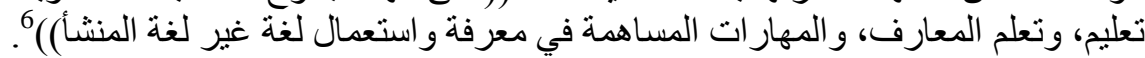

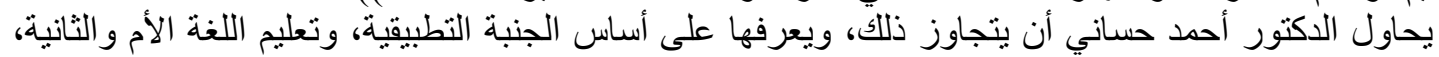

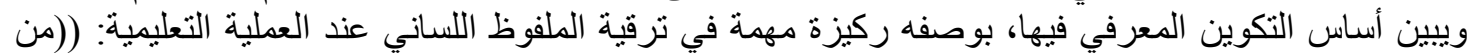

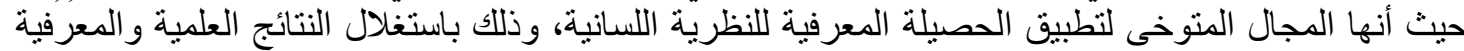

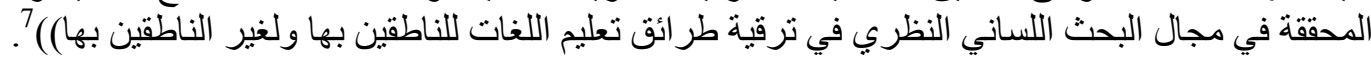

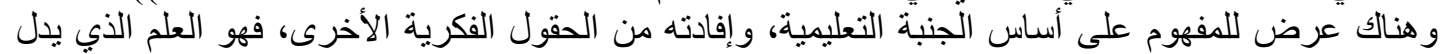

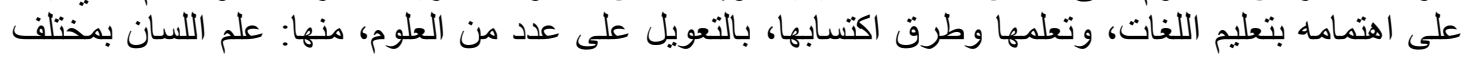

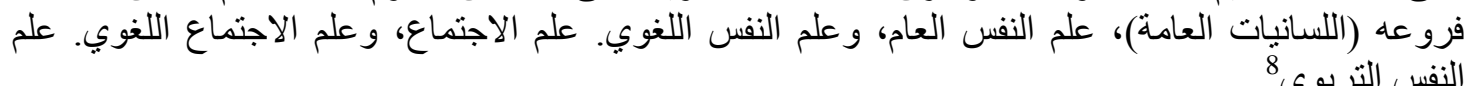

فكرة اللسانيات التعليمية، ووظيفتها، وسماتها

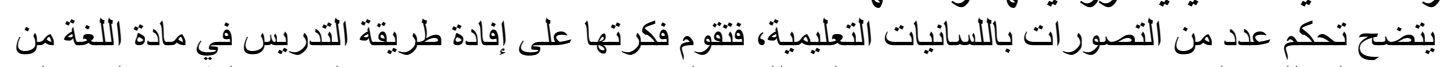

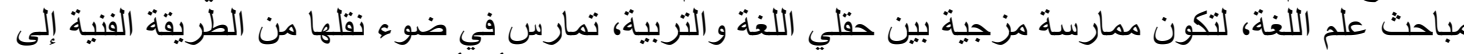

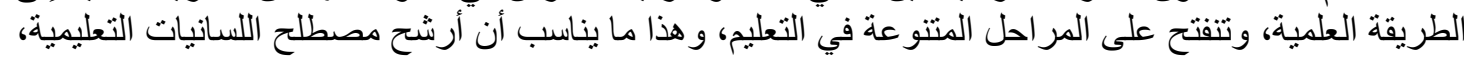

$$
\begin{aligned}
& \text { 22 ينظر: علم اللغة التطبيقي وتعليم العربية، د. عبده الر اجحي؛: 9- } 10 . \\
& 3 \text { كلم اللغة التطبيقي وتعليم العربية: } 10 .
\end{aligned}
$$

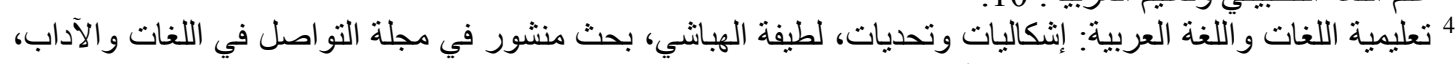

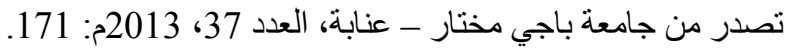

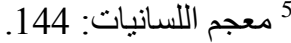

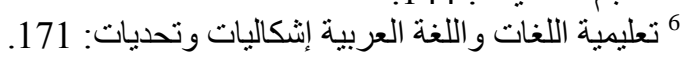

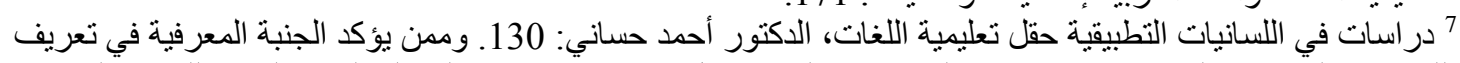

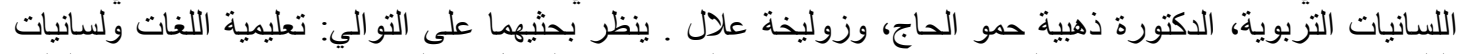

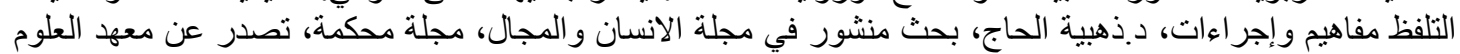

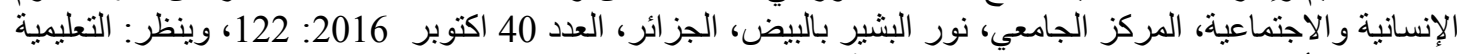

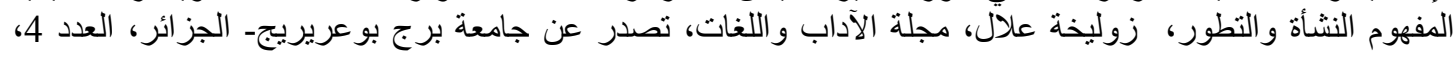

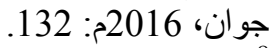

8 ينظر : علم اللغة التطبيقي وتعليم العربية: 17. 


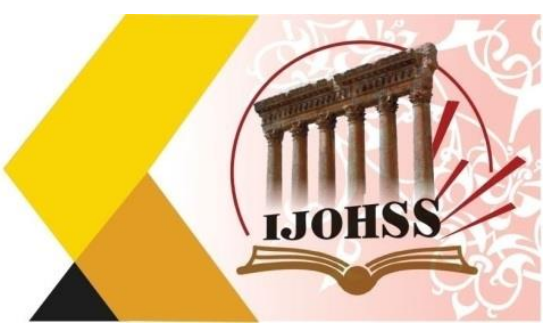

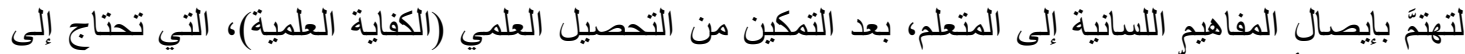

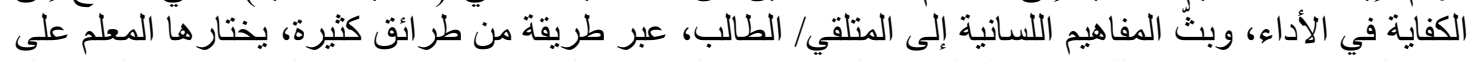

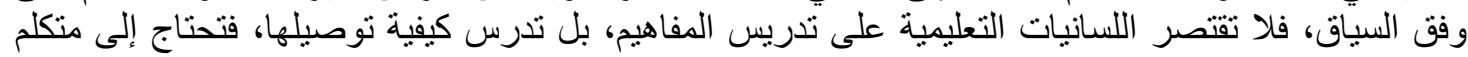

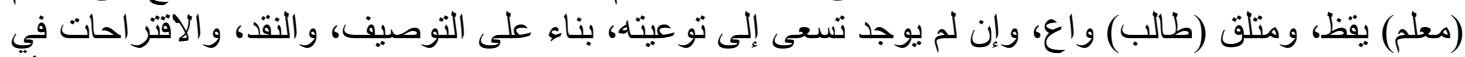

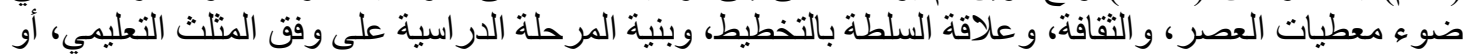

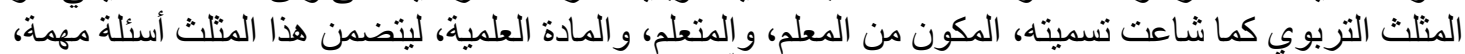

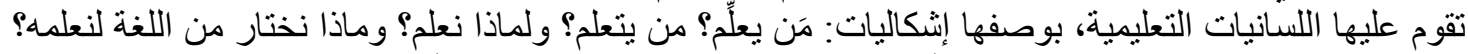

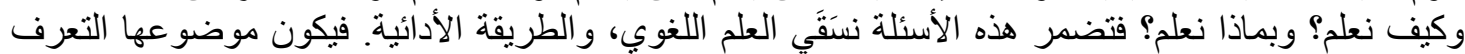

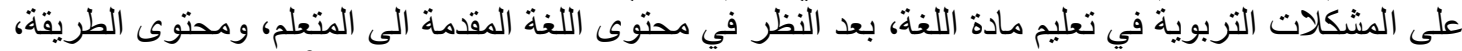

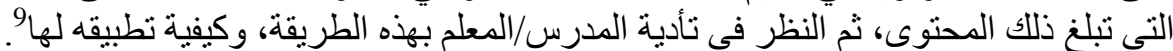

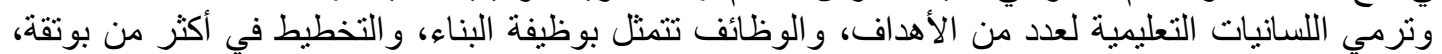

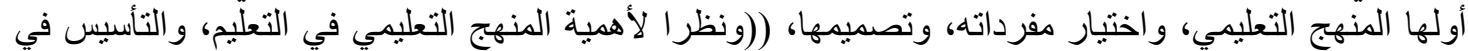

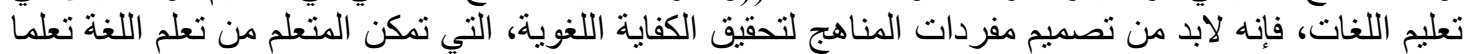

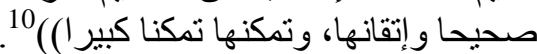

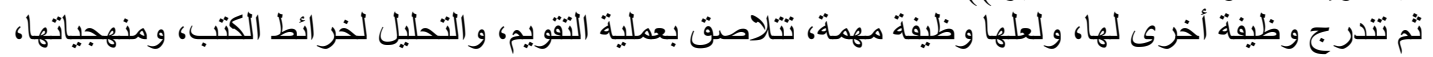

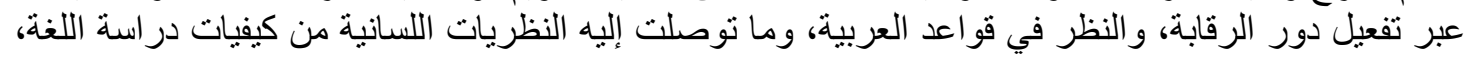

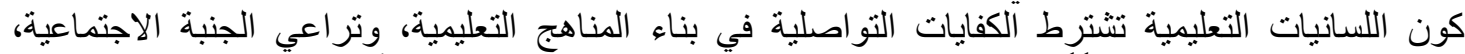

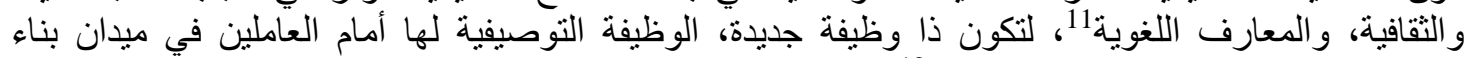

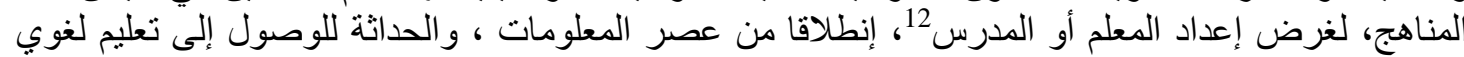

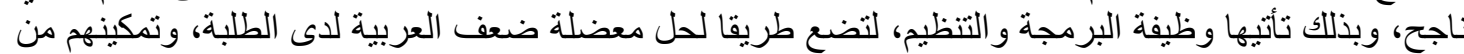

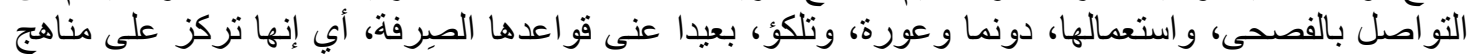

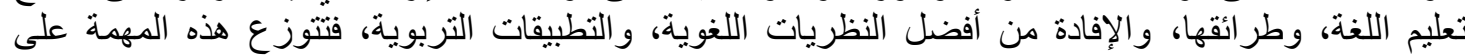

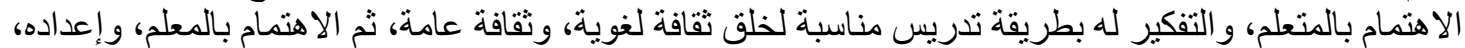

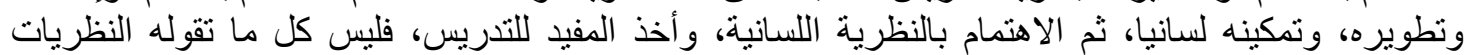

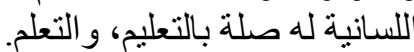
ويمكن أن يُشتق من جدوانية الها بعض السمات، التي تجعلها علما مستقلا، ومهما، وقد رصدت الدكتورة لطيفة

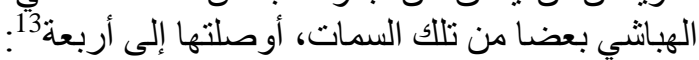

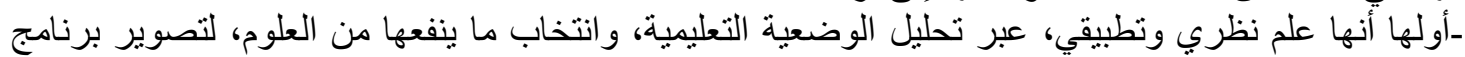

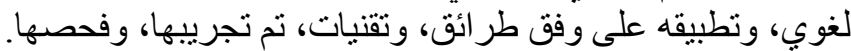

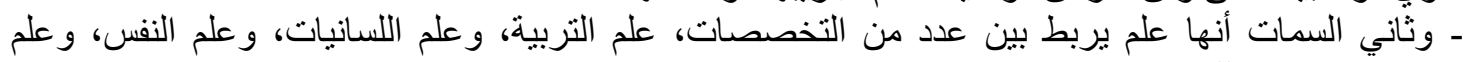

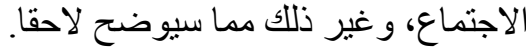

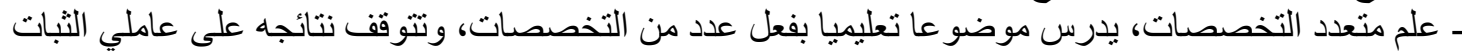

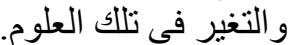

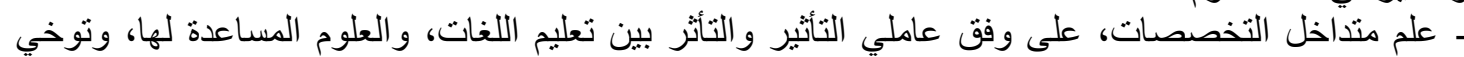
تطبيقها لغرض نرقية طر ائق التدريس. على وفئ

9 ينظر : التعليمية عند عبد الرحمن الحاج صالح، فايزة مختاري، رسالة ماجستير، كلية الأدب العربي و الفنون، جامعة عبد

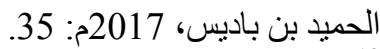
10 المنهج التواصلي فيلي في نتعليم اللغات اللغة العربية انموذجا، إيمان محمد سعيد الحلاق، رسالة ماجستير، كلية الآداب و العلوم، جامعة قطر، 2017م :

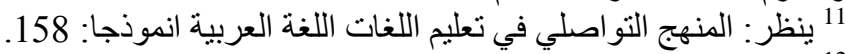

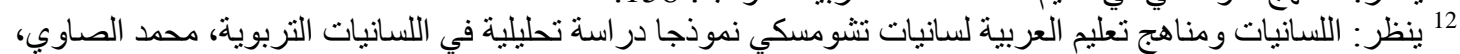

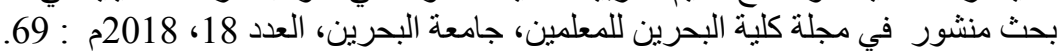
13 ينظر : تعليمية اللغات و اللغة العربية إنكاليات وتحديات، 172. 


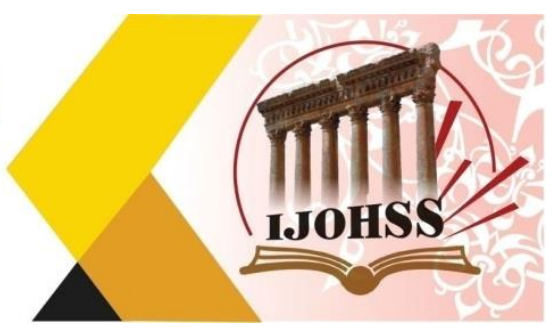

ويمكن أن أضيف عددا من السمات الأخرى، سجلتها بناء استيعاب موضو عاتها، ومنهجها:

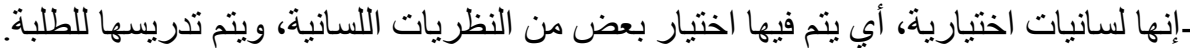

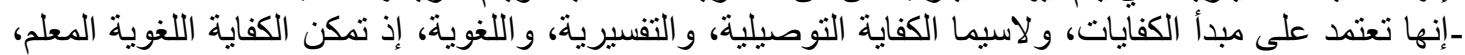

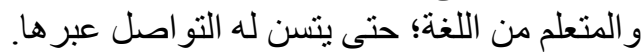
ـ ـ إنها لسانيات تخطيطية، وتعنمد خاصية التفكير، و التجربة، والتهنية والفحص، فتخطط لدراسة اللغة، ويسمي الدكتور

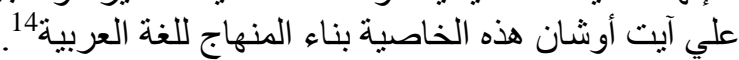

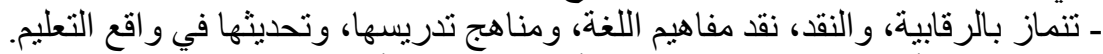

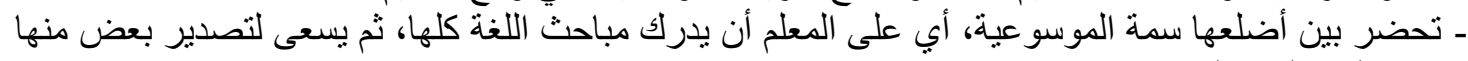

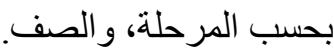
ـ ـ وتتأسس على سمة الموسو عية سمة الانتقائية، بانتخاب بعض المعلومات اللغوية، وتقديمها للطالب في درس

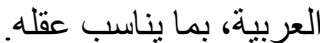

ـ متقولبة بحسب البيئة التي تطرح بها، فقد بختلف و اقعها في سوريا عن و اقعها في لبنان، وكذلك تختلف عنهما

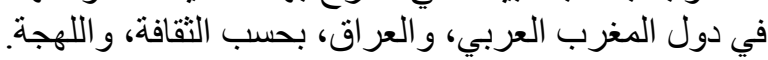

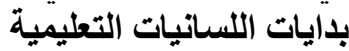

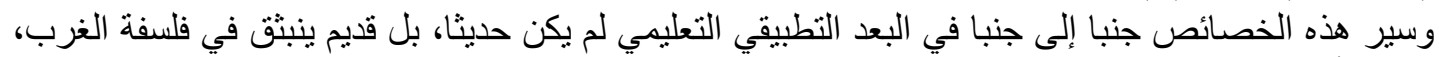

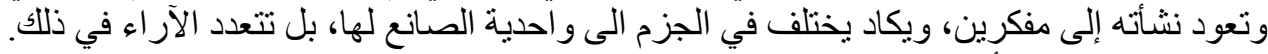

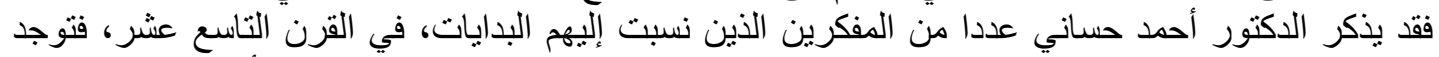

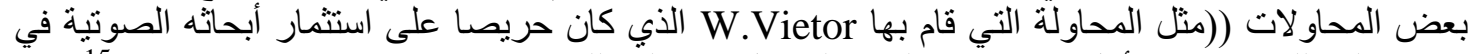

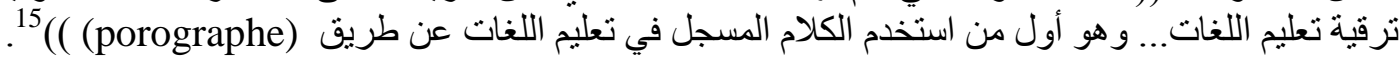

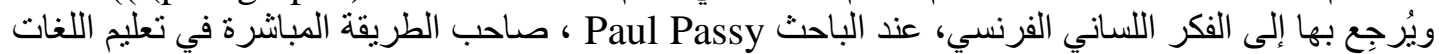

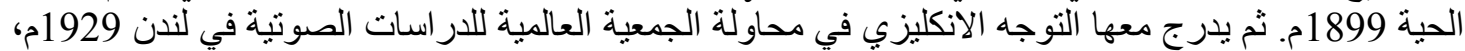

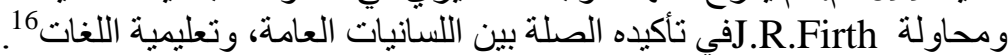

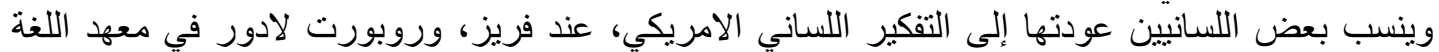

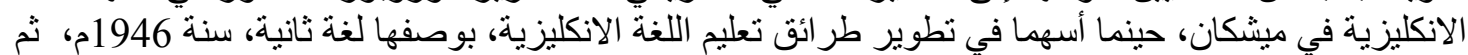

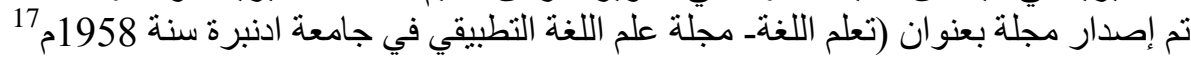

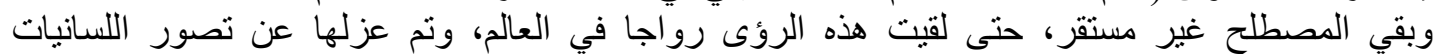

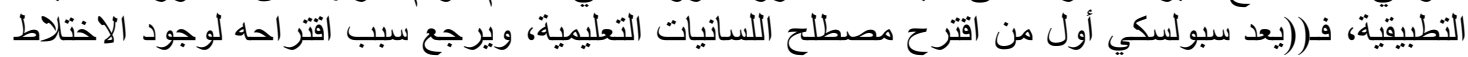

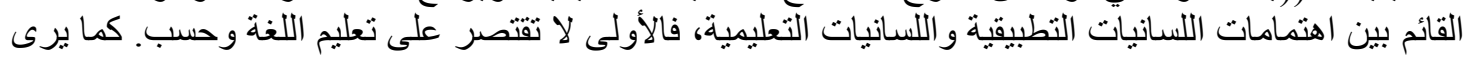

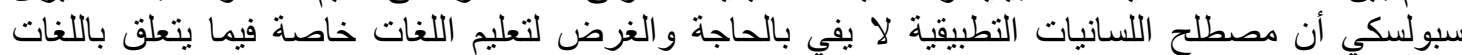

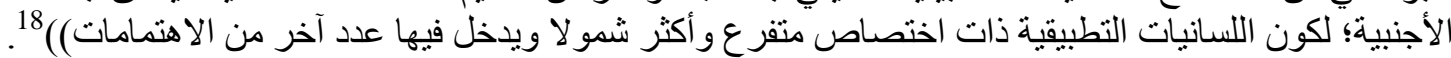

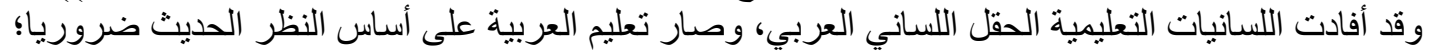

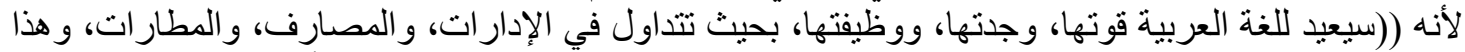

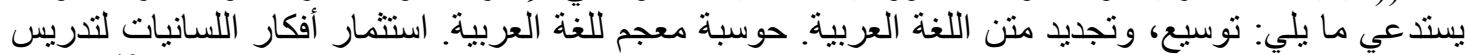
اللغة العربية. أستثمار غنى التراث اللغوي، و البلاغي، و النقدي العربي القديم لتطوير اللغة العربية))19، فتسهر

$$
\begin{aligned}
& 14 \text { ينظر : اللسانيات و التربية المقاربة بالكفايات و التدريس بالمفاهيم، علي ايت اوشان: } 91 .
\end{aligned}
$$

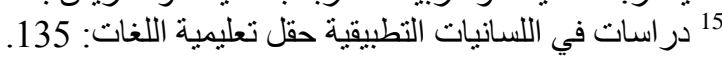

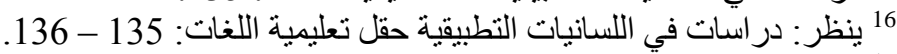

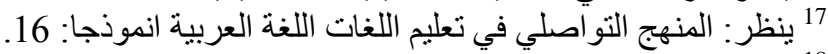

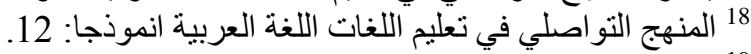

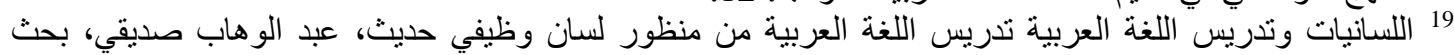

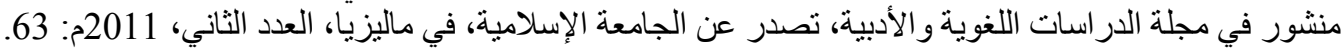




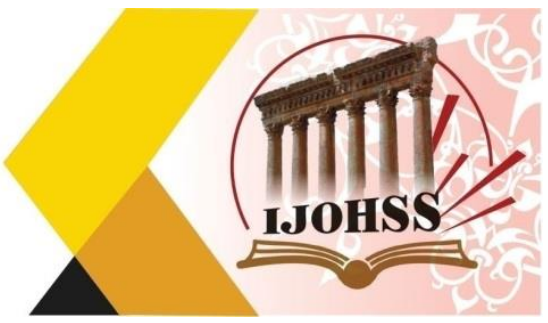

هذه اللسانيات بتطوير مناهج التعلم والتعليم، وتحقق الجودة العالية فيهاه، على أساس منهاجية تتخذها تقوم على 21 أ_التحليل اللساني للمو اد الدر اسية اللسانية، بعيدا عن التلقين، بل ايمانا بالتندريس بالكفايات.

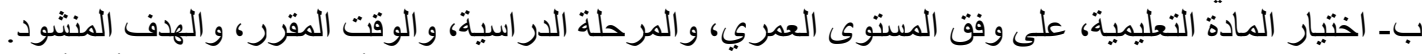

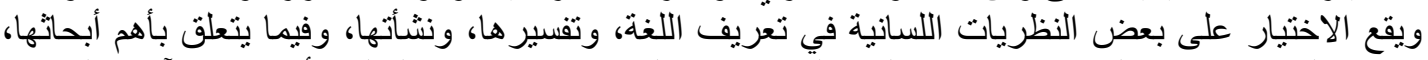

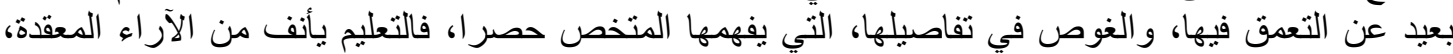

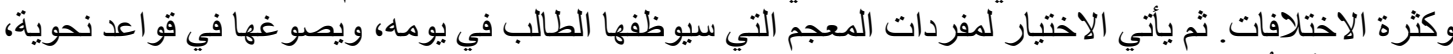

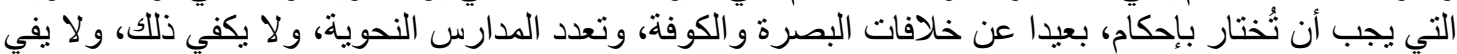

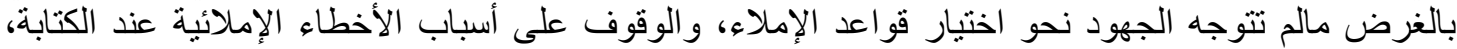

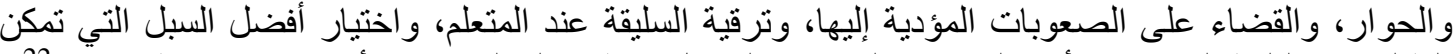

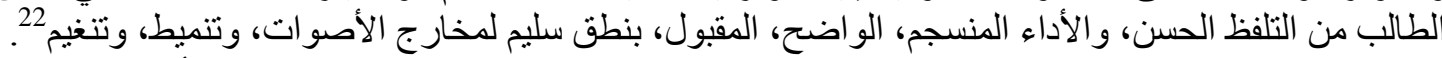

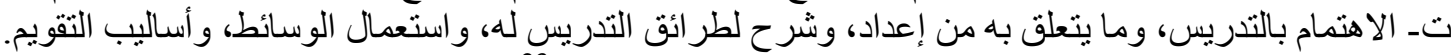

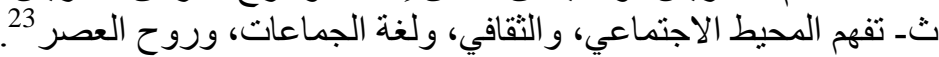
مرتكزات اللسانيات التعليمية النية

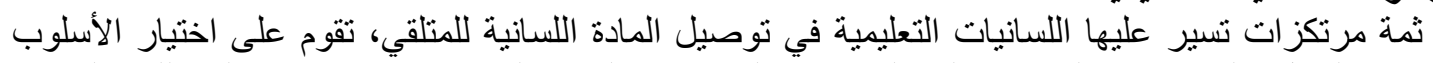

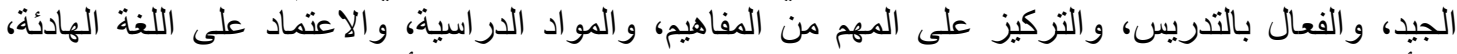

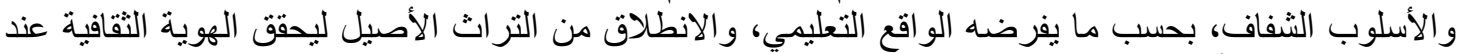

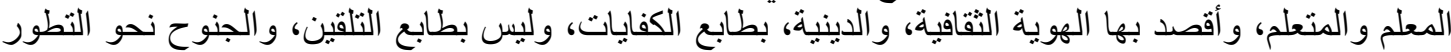

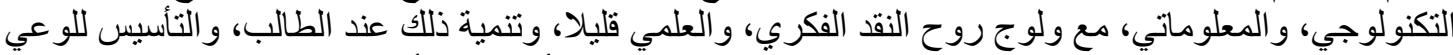

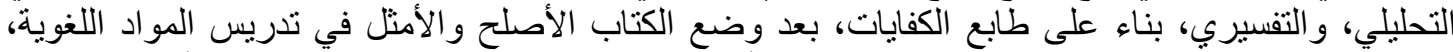

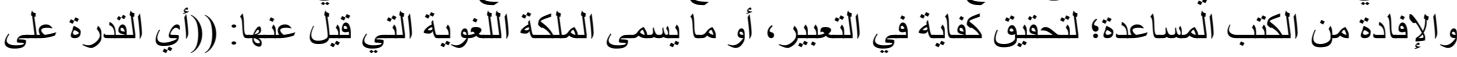

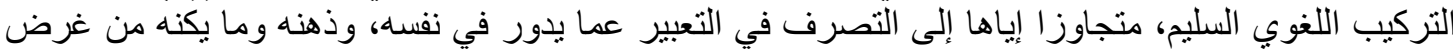

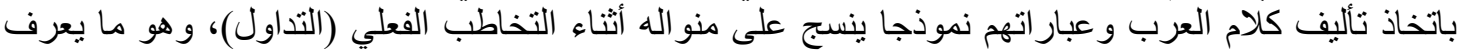

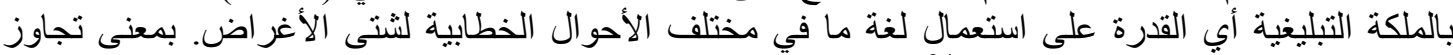

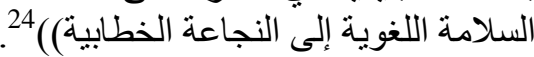

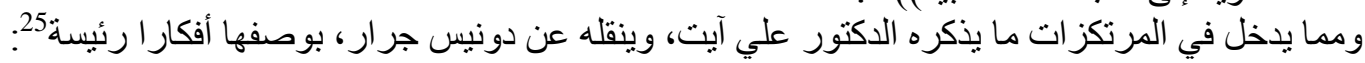

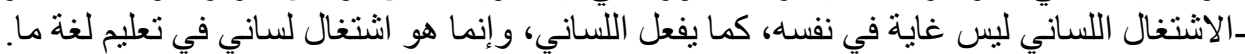

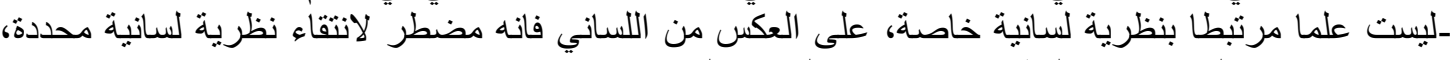
فيمكنه الاعتماد على عدد من النظريات فيما ينفع الوضع البيدانئ الئوجي.

20 ينظر: البحث العلمي ودوره في جودة التعليم، أبو بكر العزاوي، بحث منشور في المجلة المغربية للتربية، العدد 8،

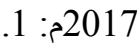
21 ينظر: تعليمية اللغات بين معيارية اللسانيات والتجدد المنهجي، صر اع محمد، بحث منشور في مجلة المقري للار اسات

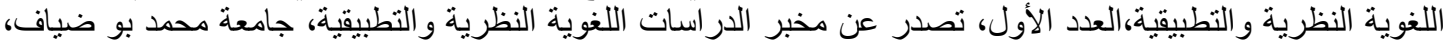

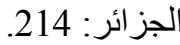
22 ينظر : دراسات في اللسانيات التطبيقية حقل تعليمية اللغات: 148.

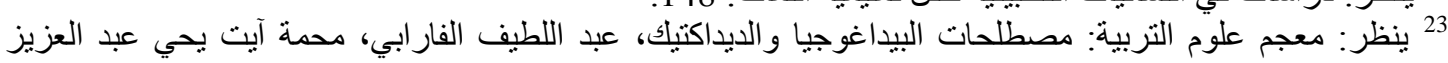
الغرضاف، عبد الكريم غريب: 256.

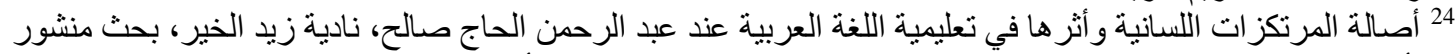

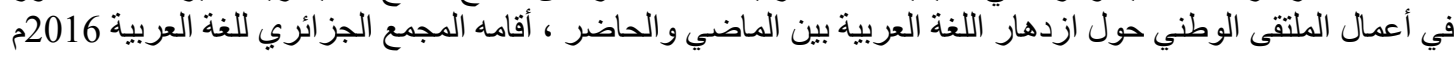




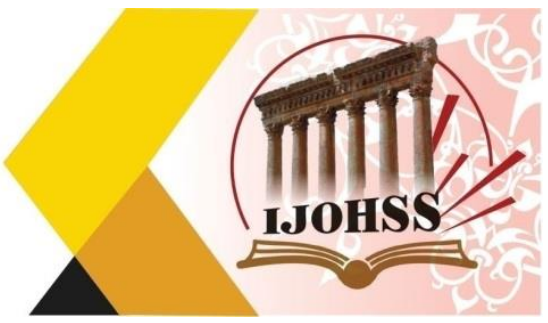

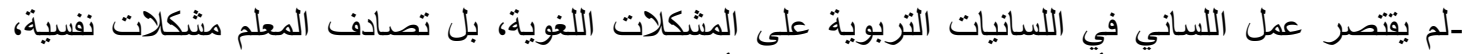

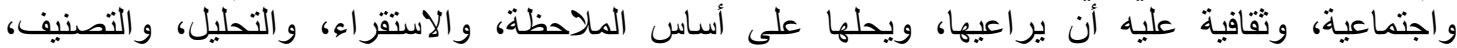

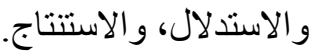
اتجاهات اللساتيات التعليمية التاجية

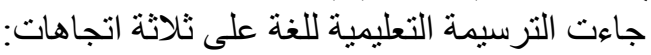

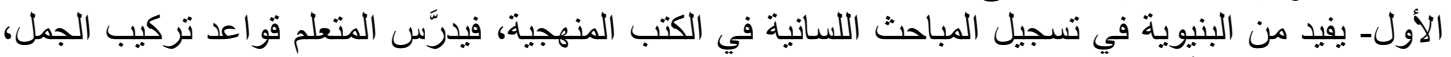

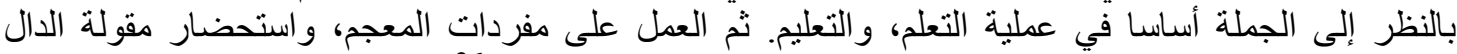

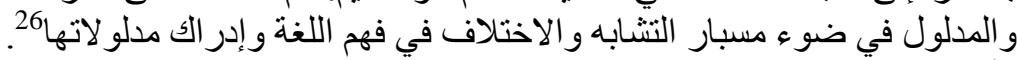

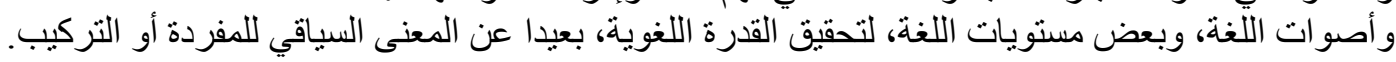

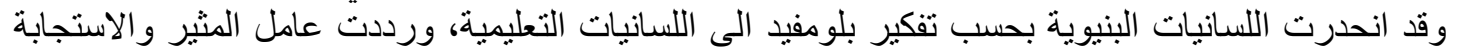

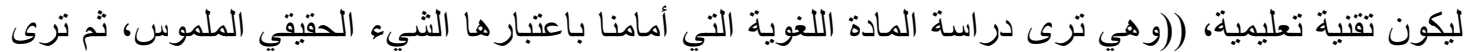

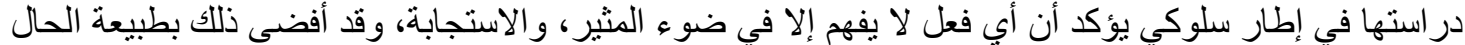

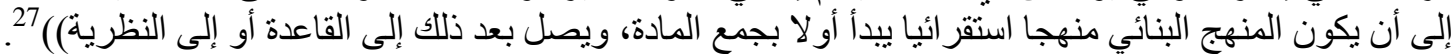

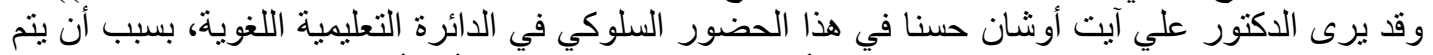

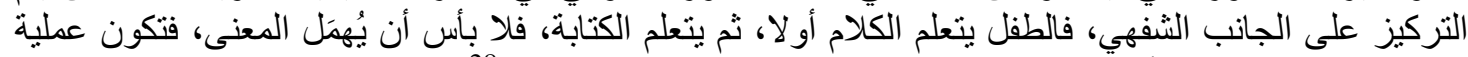

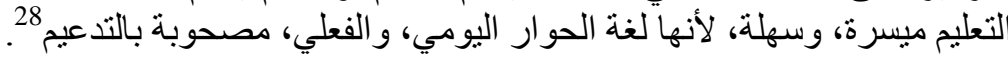

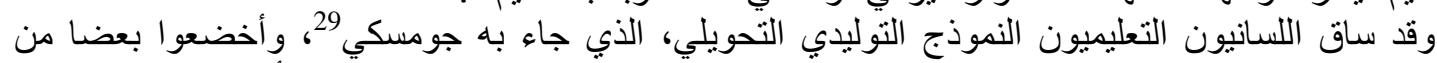

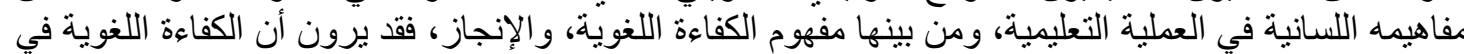

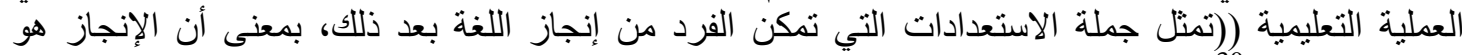

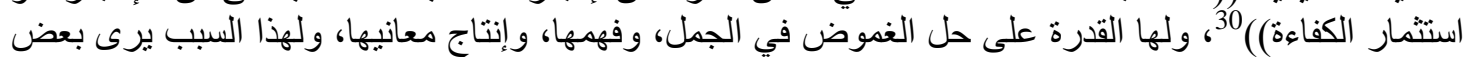

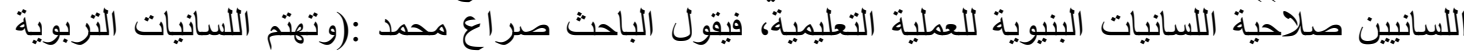

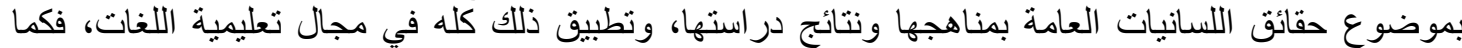

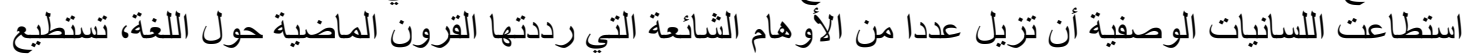

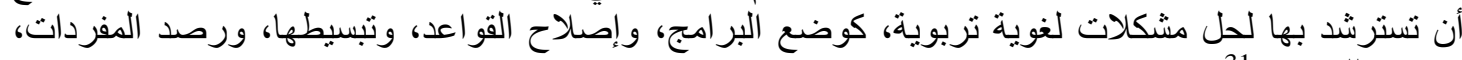

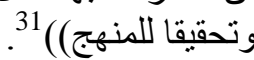

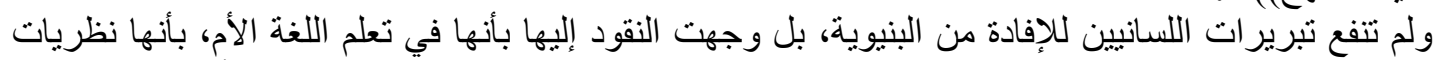

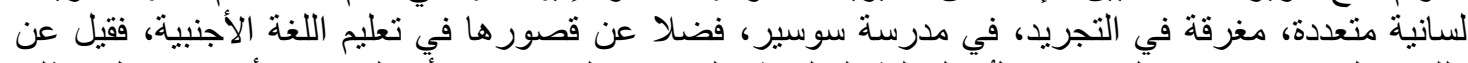

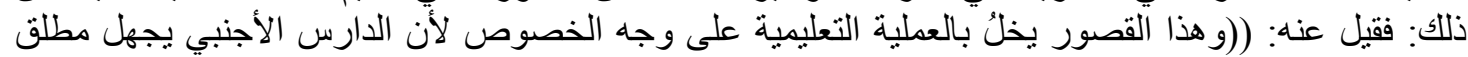

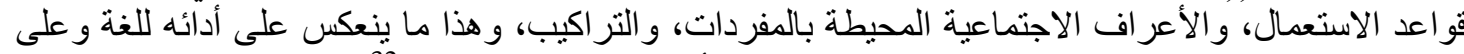

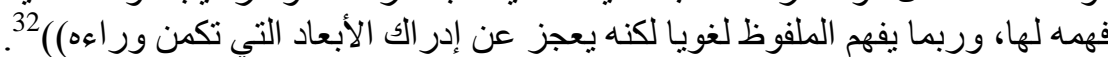

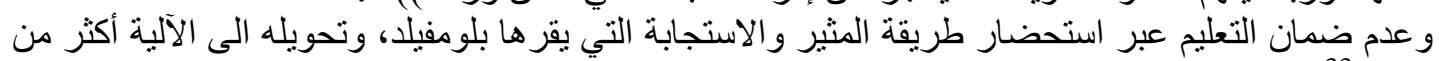

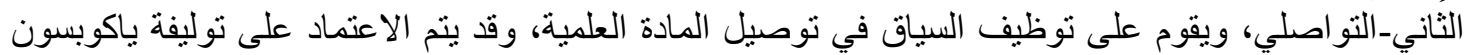

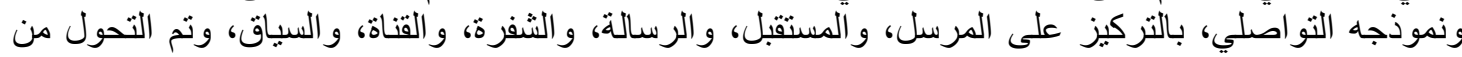

26 ينظر : اللسانيات و التربية المقاربة بالكفايات و التدريس بالمفاهيم: 21. 27 علم اللغة التطبيقي وتعليم العربية: 19.

28 ينظر : اللسانيات و التربية المقاربة بالكية: الكفايات و التدريس بالمفاهيم: 23.

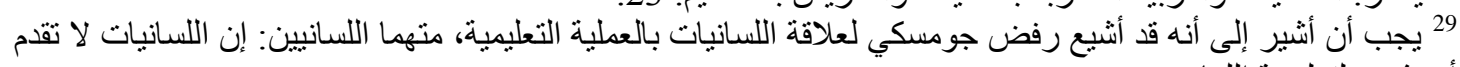

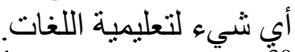
30 التعليمية المفهوم النشأة و التطورية 144.

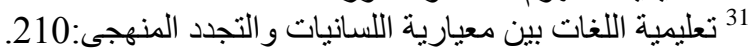

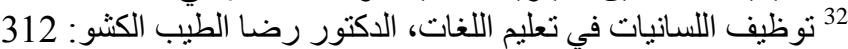
33 ينظر : اللسانيات ومناهج تعليم العربية لسانيات نتو مسكي نموذجا در اسة تحليلية في اللسانيات التربوية: 70. 


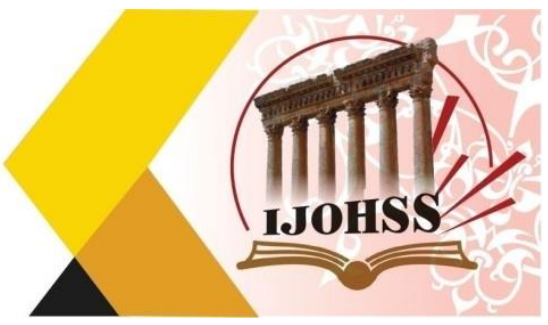

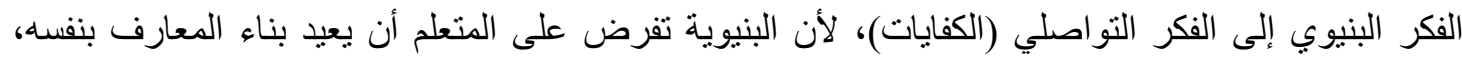

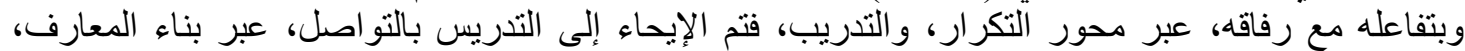

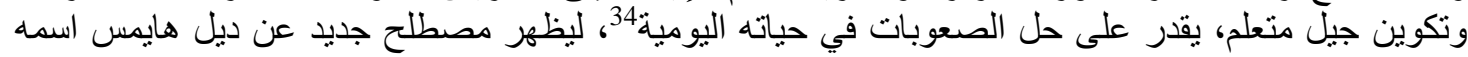

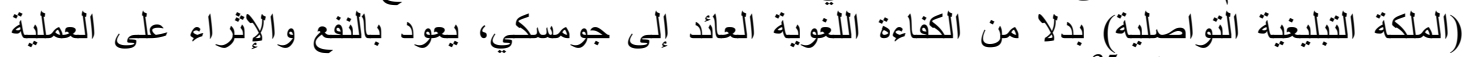

التعليمية في الجو انب الآتية:35. ـتجعل من المتعلم يمنلك القدرة التو اصلية للغة في سياق الاستعمال، وتحديد المقاصد.

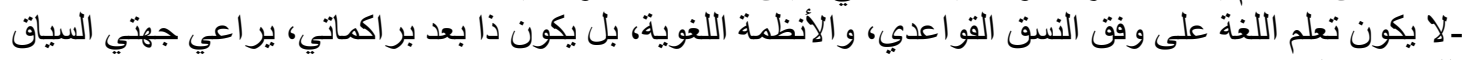

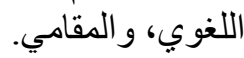

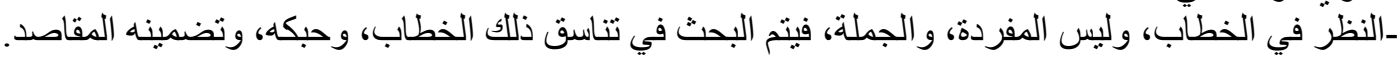

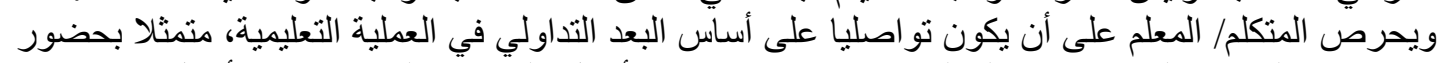

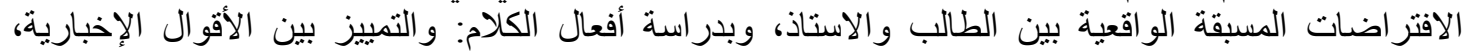

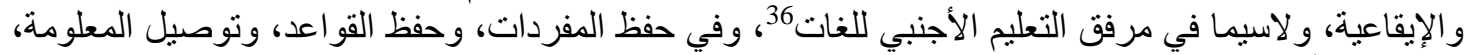

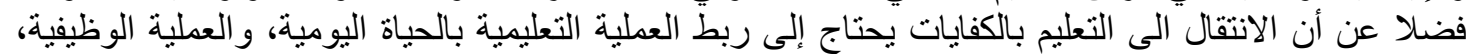

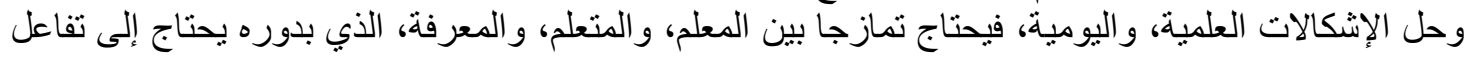

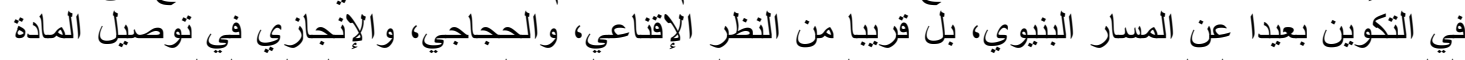

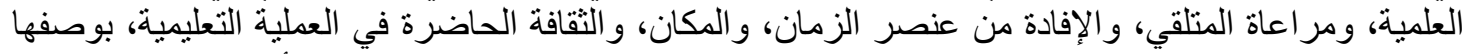

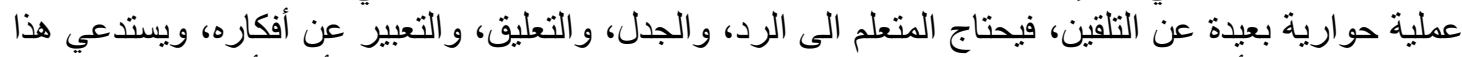

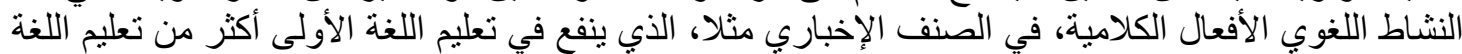

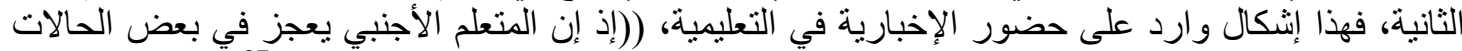

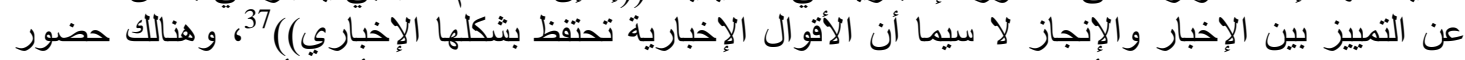

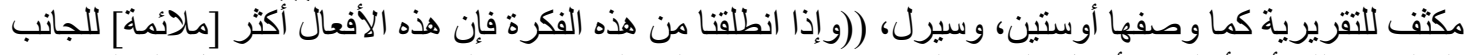

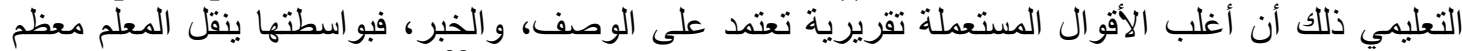

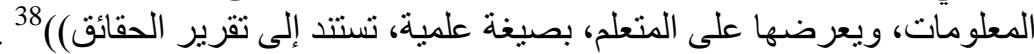

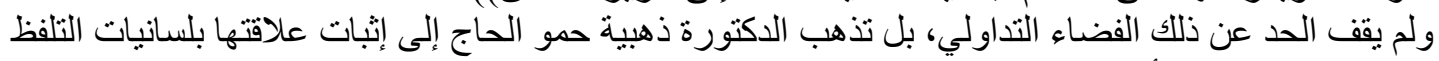

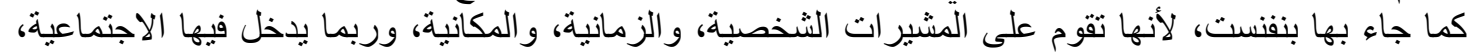

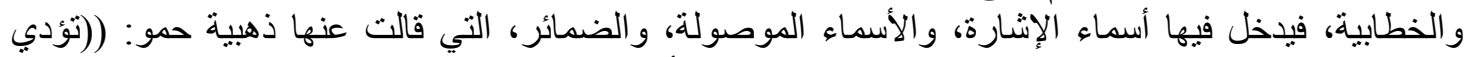

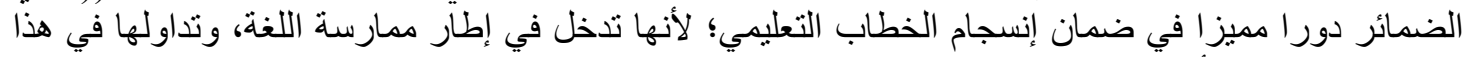
السياق، إضافة إلى أن ظاهرة الإضمار في اللغة تجعل المتنكلمين يضطرون إلى إلى اكتساب قدرة الإحالة، والإنشارة

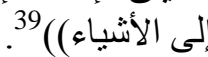

ويحتاج إنجاح العملية التعليمية أن يفيد من إيقونة التفاعل التي تؤمن بعدد من المبادئ الحوارية بحسب ماتبات التركها

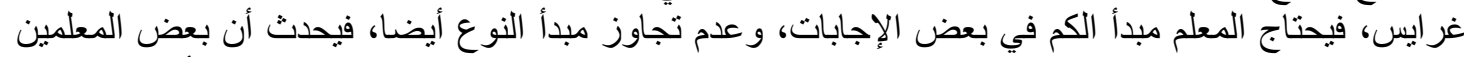

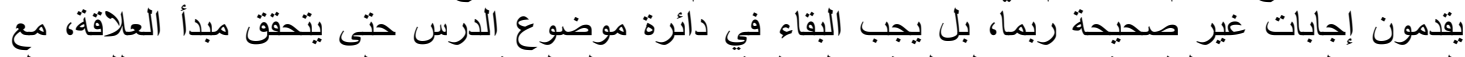

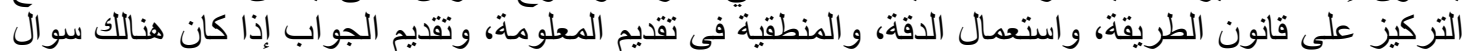

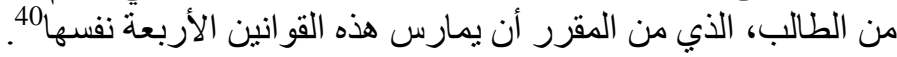

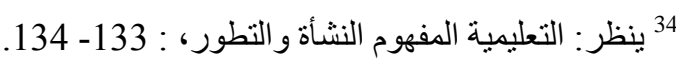

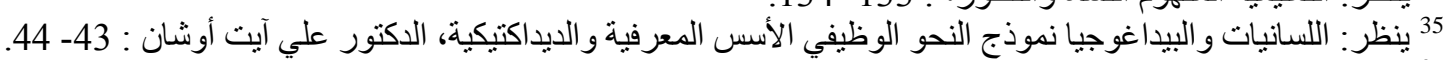

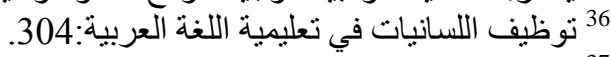

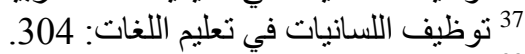

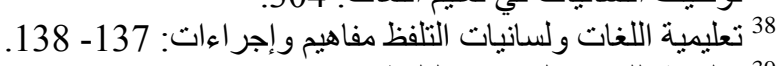

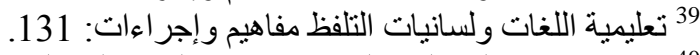

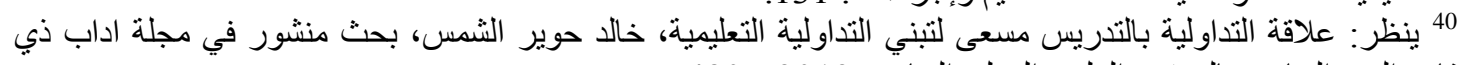

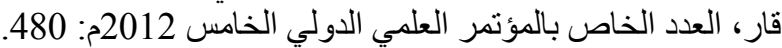




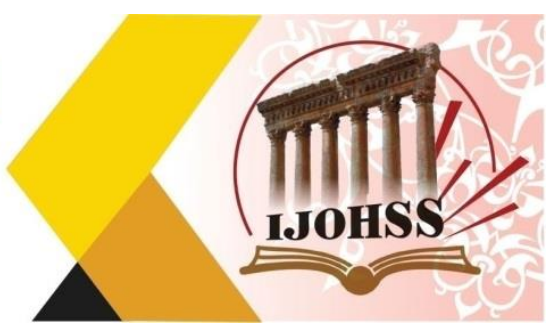

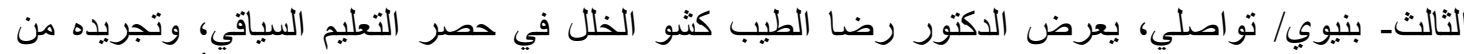

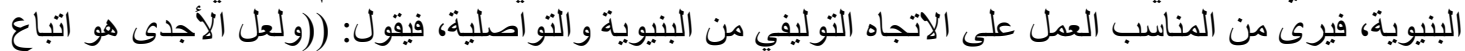

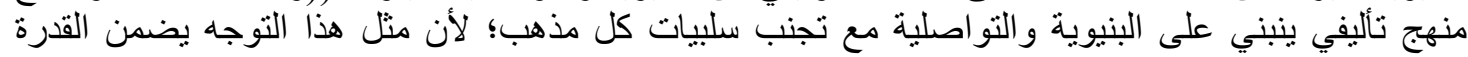

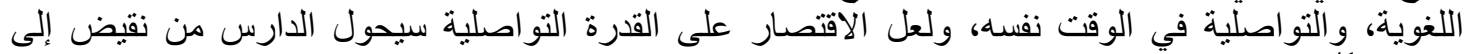
نقيض)

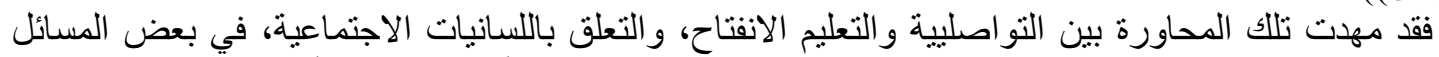

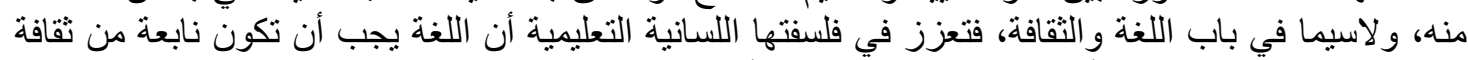

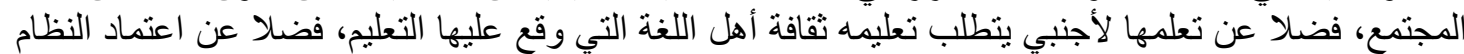

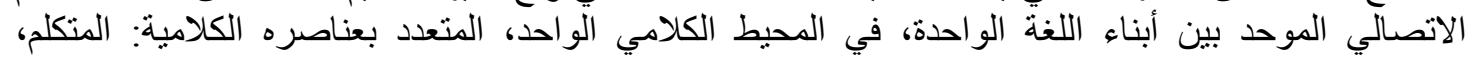

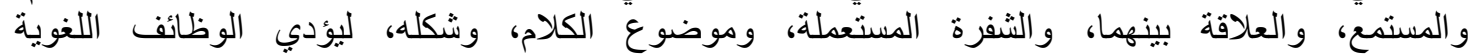

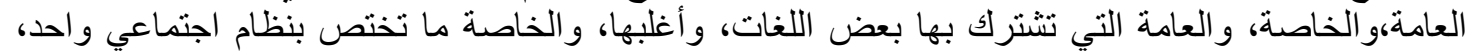

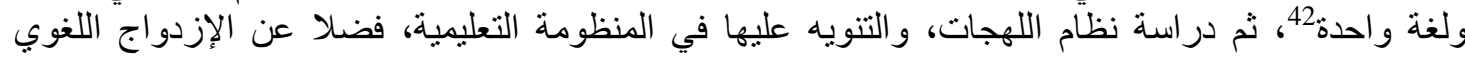
بوصفه مبحثنا مهما في اللسانيات الاجتماعية.

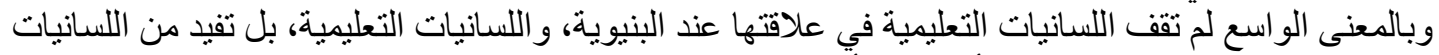

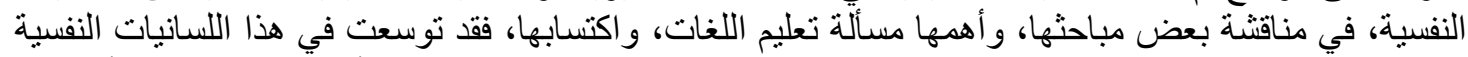

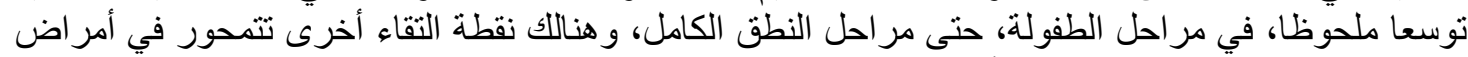

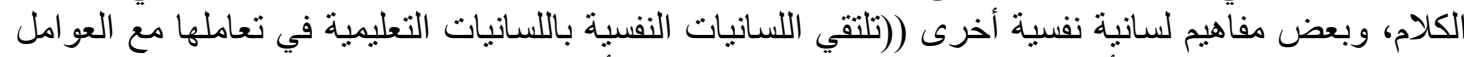

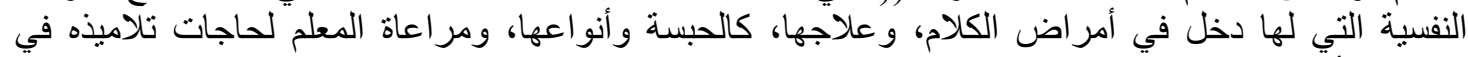

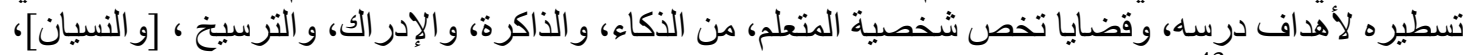

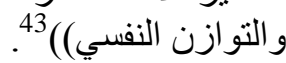

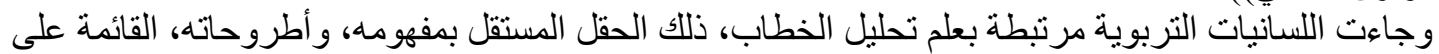

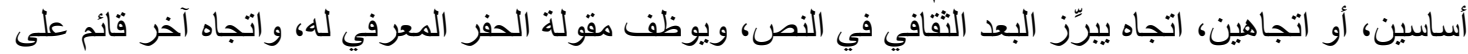

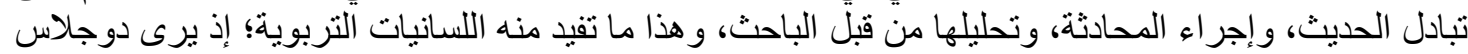

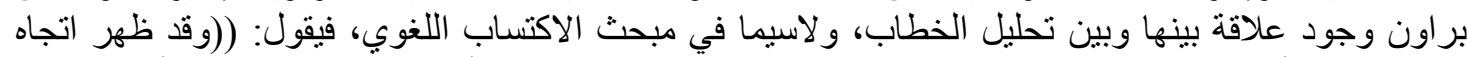

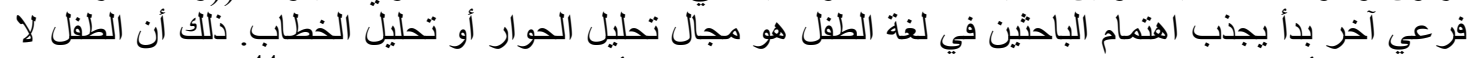

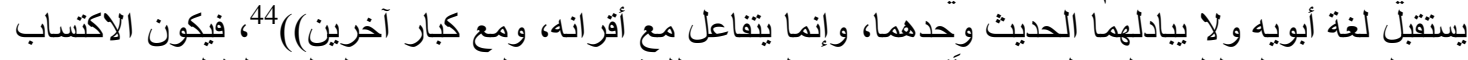

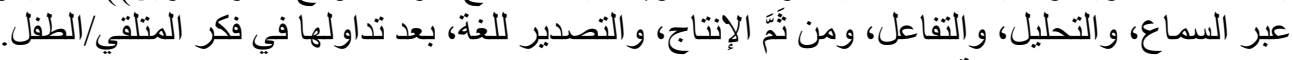
مبادئ اللسانيات التعليمية، تلبية ثمة مبادئ للسانيات التعليمية، بمثابة قو اعد أساسية لا تستغني عنها، في معالجة الو اقع التعليمي، وخطابه، فمن تانلك المبادئ: ـمبدأ المنطوق، الذي يعطي الحق المنطوق من اللغة، و الخطاب الثفوي، فيما أكده أبن جني من القدماء، وسوسير

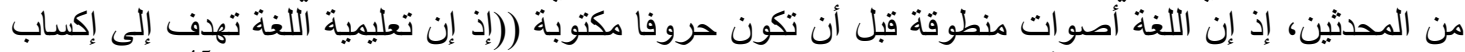

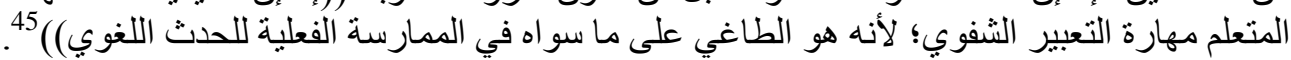

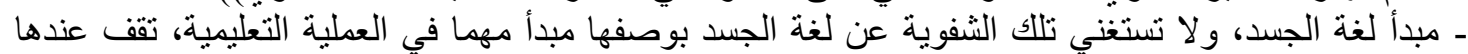

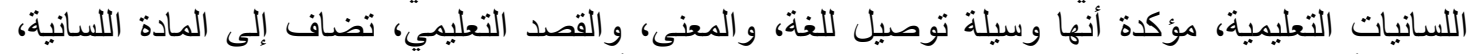

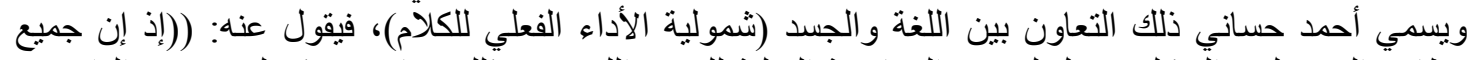

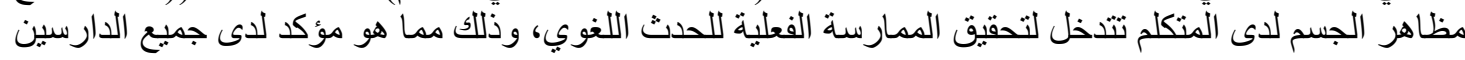

41 41 توظيف اللسانيات في تعليم اللغات: 314.

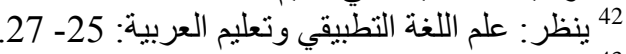

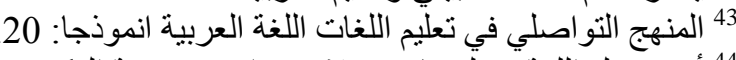

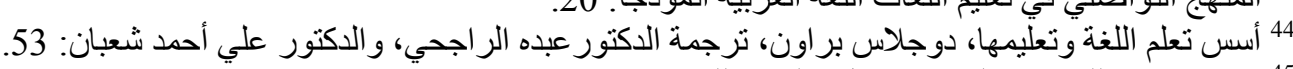
45 در اسات في اللسانيات التطبيقية حقل تعليمية اللغات: 132. 


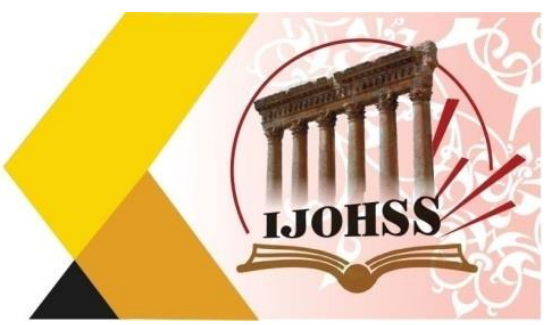

اللسانيين، و علماء النفس، المهتمين بالظاهرة اللغوية الذين يقرون بأن استعمال اللغة بشمل مظاهر الفرد المتكلم-

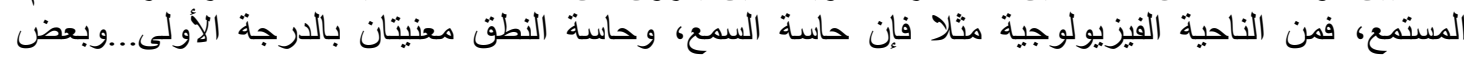

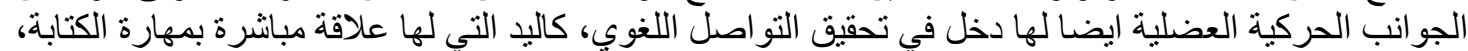

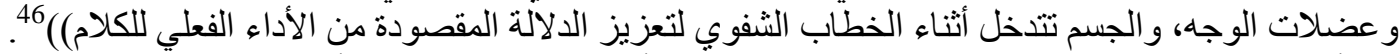

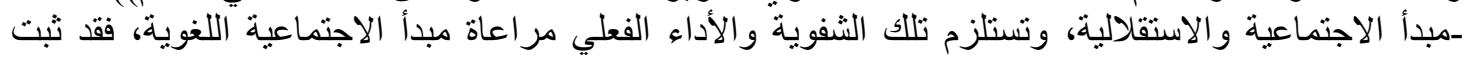

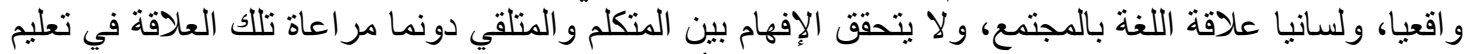

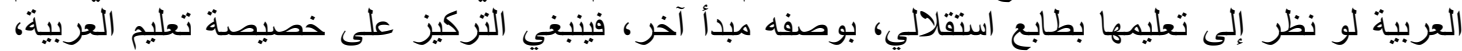

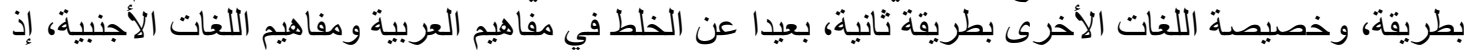

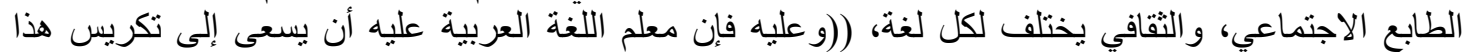

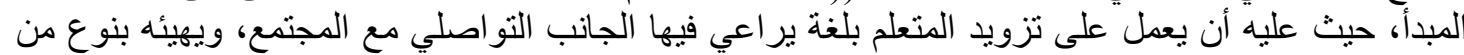

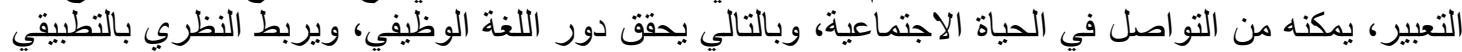


ـمبدأ العقد التعليمي، أي تبادل أطراف العلاقة بين المعلم و المتعلم، لتحقيق التفاعل، وتقديم اللغة المتوخى تعليمها،

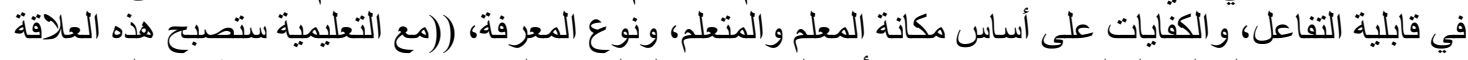

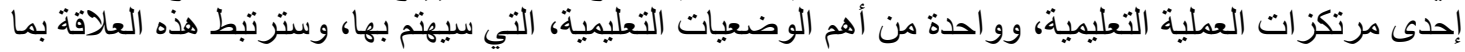

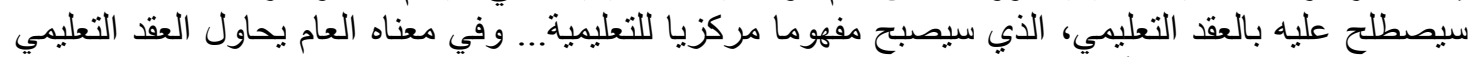

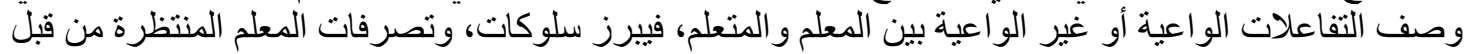

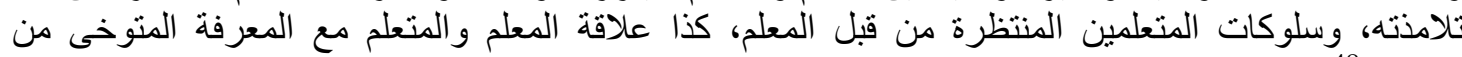

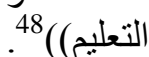
ـمبدأ التصور)، التصات، أو التمثلات، فقد يقتنع اللسانيون التعليميون أن الديداكتيك يقوم على المعرفة المسبقة التي

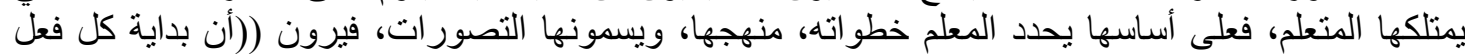

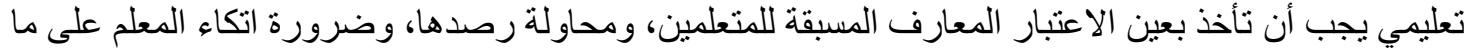

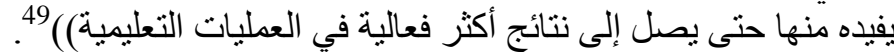
- مبدأ الآلية، بمكن أن أثنير إلى العلاقة الكبرى بئل فين التعليم أو التعليم اللغوي والآلية بأنواعها المتعددة، كونها

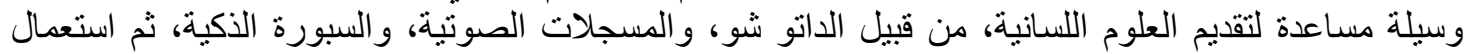

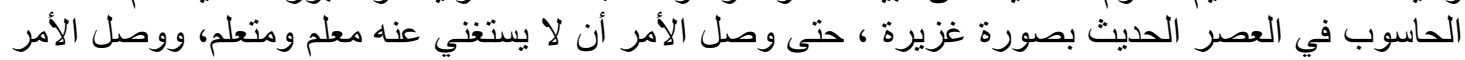

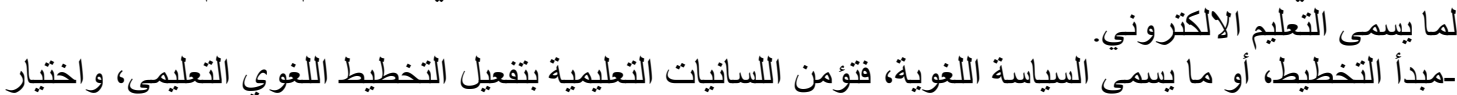

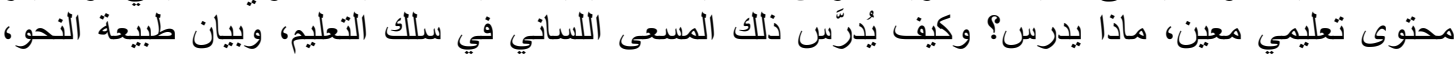

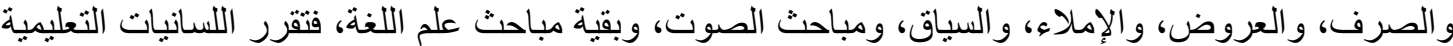

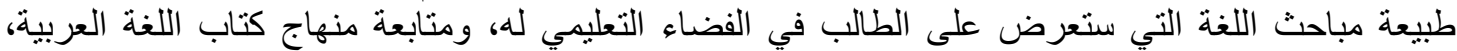

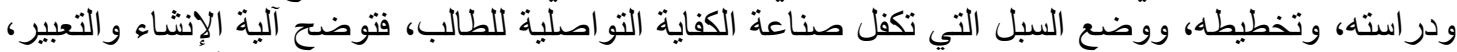

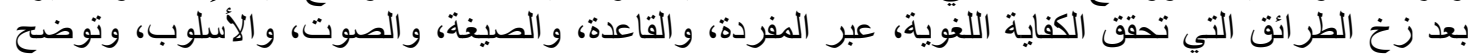

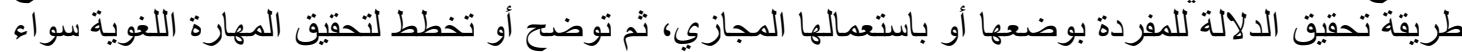

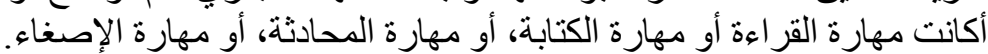

46 در اسات في اللسانيات التطبيقية حقل تعليمية اللغات: 132. 47 تعليمية اللغة العربية من منظور اللسانيات الحديثة والطرائق التربوية، التئية الدكتور أحمد مداني، بحث منشور في مجلة

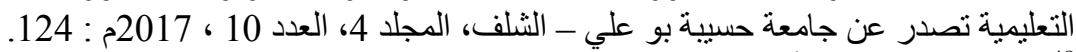
48 تعليمية اللغة بين الأحادية والتعدد، ميمون مجائ مجاهد، اطروحة دكتور اه، كلية الآداب واللغات و الفنون، جامعة وهران،

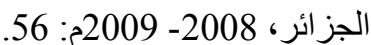
49 تعليمية اللغة بين الأحادية و التعدد: 58. 


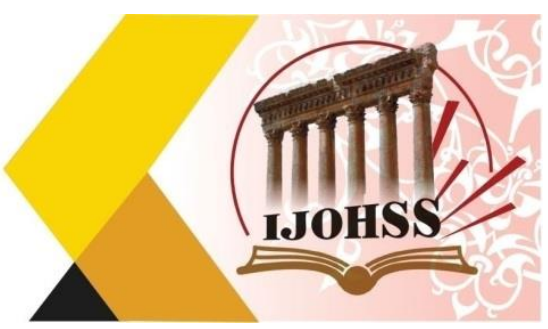

ويقترب التخطيط اللغوي التعليمي من رؤية الدولة، و الأمن القومي (ورأى فشمان أن التخطيط اللغوي يثير

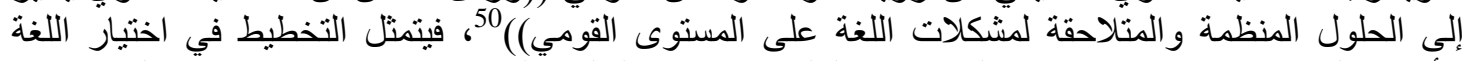

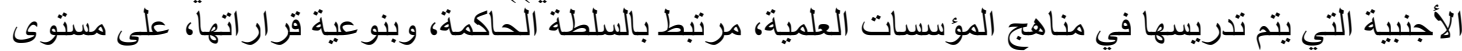

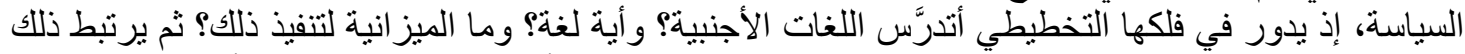

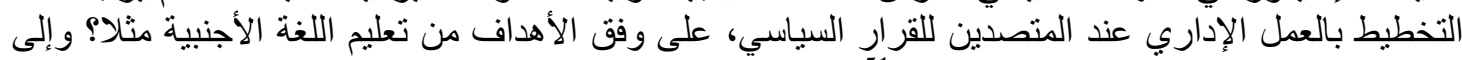

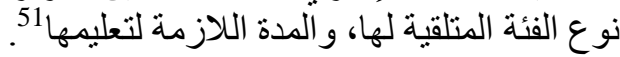

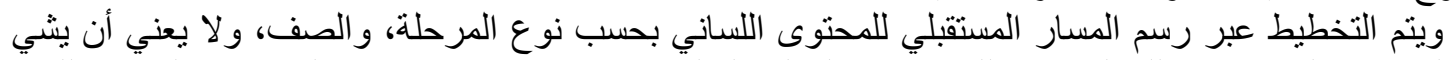

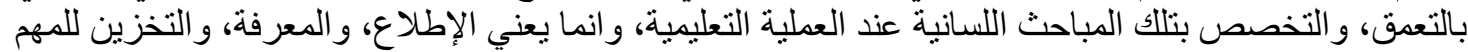

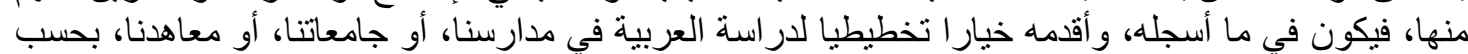

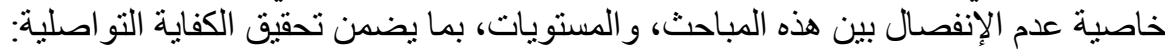

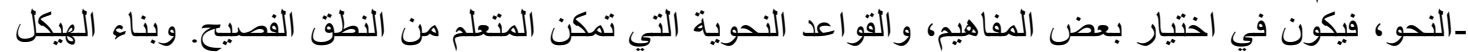

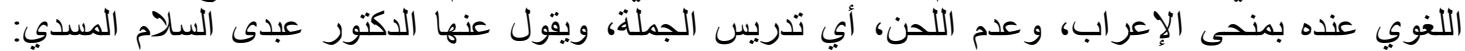

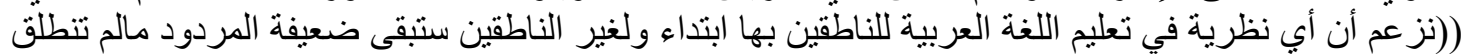

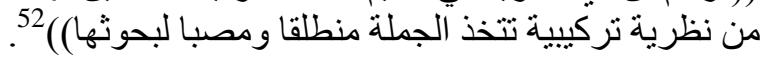

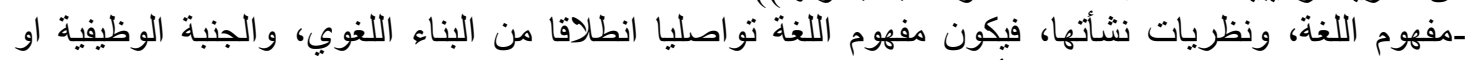

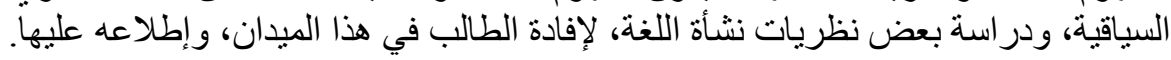

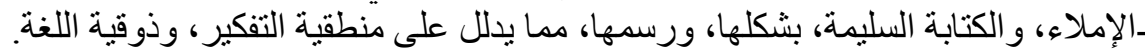

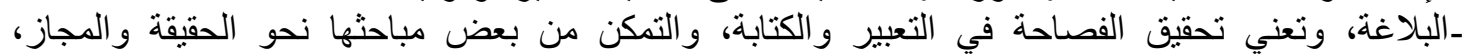

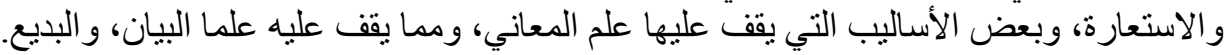

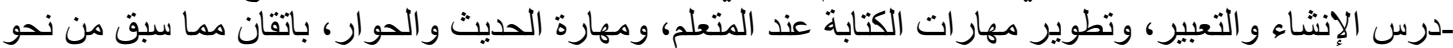
، وبلاغة، و إملاء، ثم توصيل المر اد نوصيله فيله في فكر المتعلم.

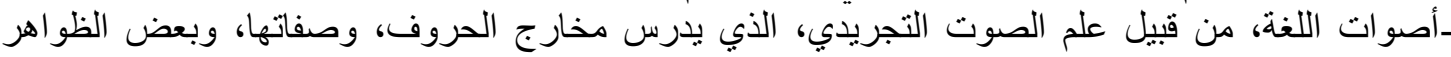

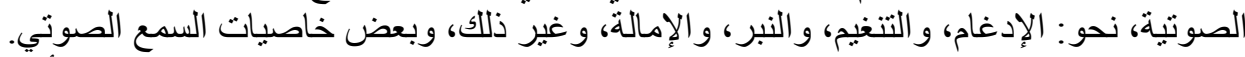

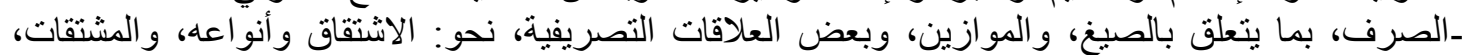

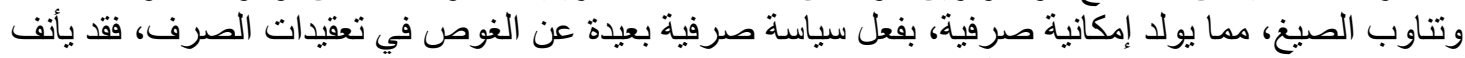

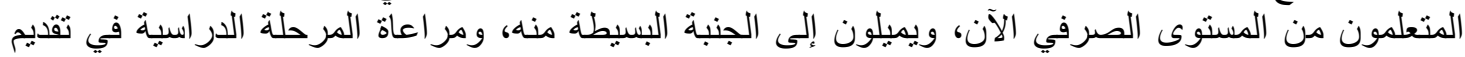

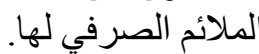

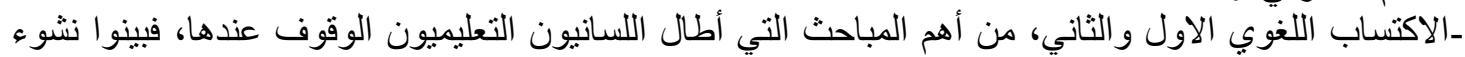

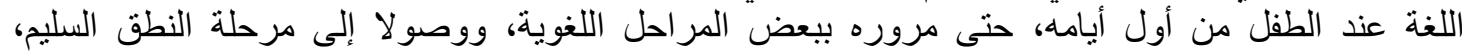

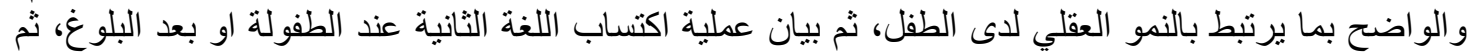

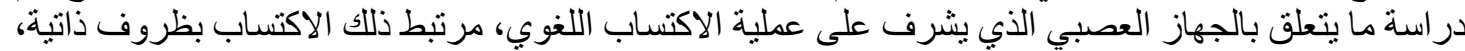

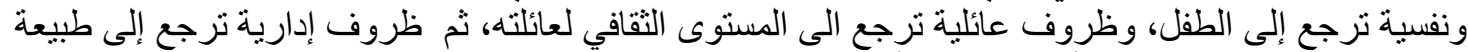

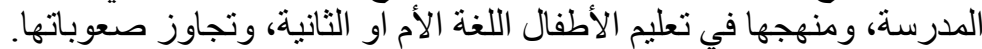

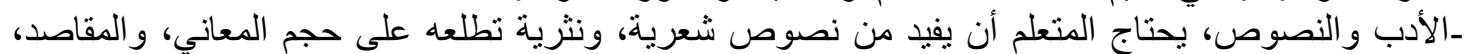

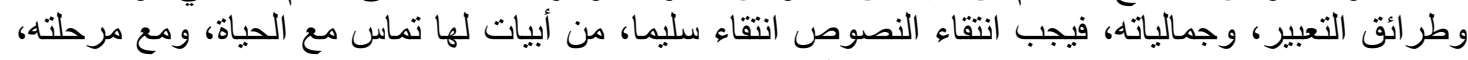

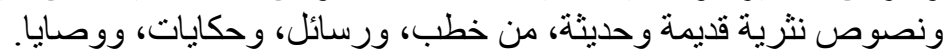

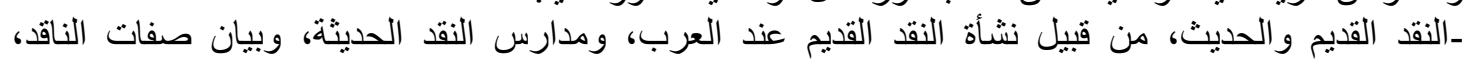
ومرجعياته، وسبل تعامله مع النص الأدبي.

الوا واقع التخطيط اللغوي للخطاب التعليمي دراسة وصفية في كتب تعليم اللغة العربية للناطقين بغيرها في الوطن العربي، الدكتور خالد عبد الكريم بسندي: 20.

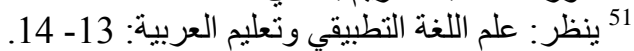
52 مباحث تأسيسية في اللسأنيات، الدكتور عبد السلام المسدي: 230. 


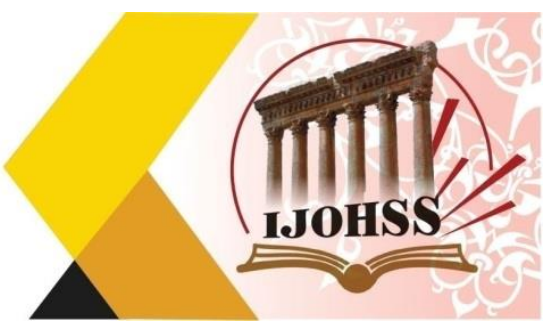

ــالعروض، ليتم عرض أهم المفاهيم العروضية، وبحور الثعر ، وما يعتريها من تغييرات، من زحافات، وعلل، وتندوير، و وغير ها.

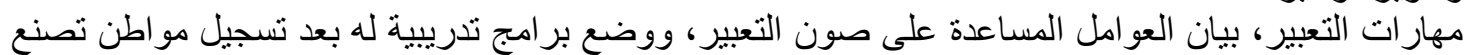

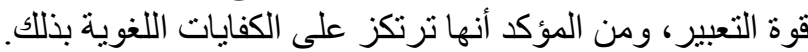

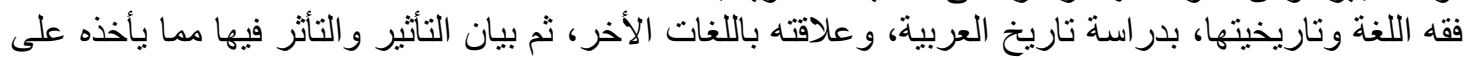

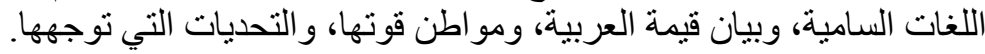

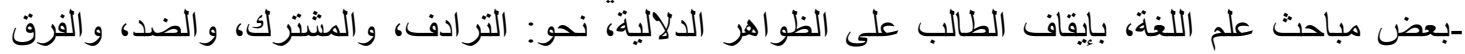
اللغوي، والمثلث اللغوي، والتطورات اللغوية والدلالية للمفردات، فضلا عن الاقتراض اللغنية اللغوي، والمعرب،

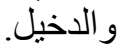

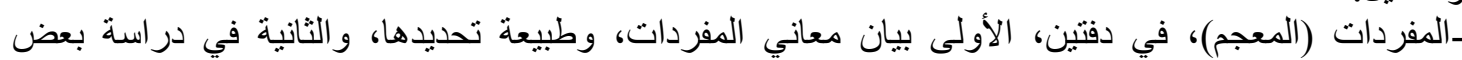

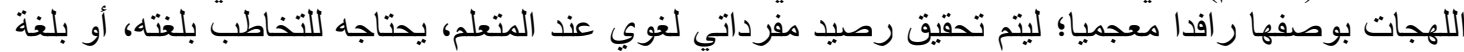

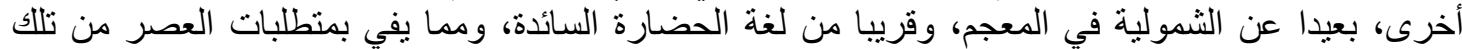

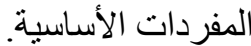

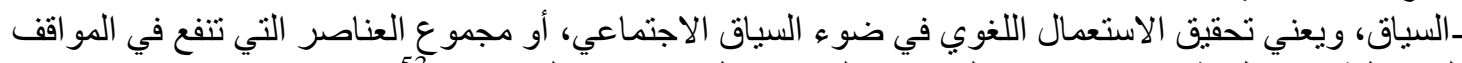

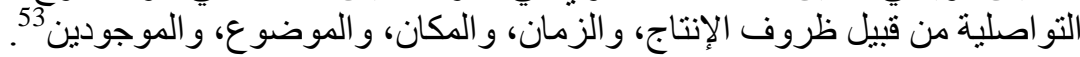

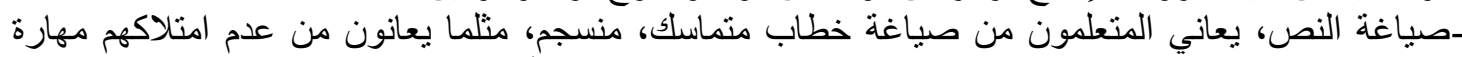

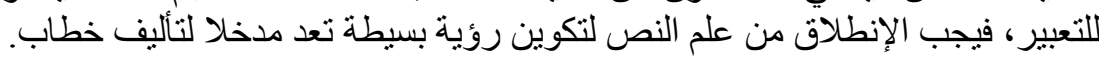

تجليات البينية في اللسانيات التعليمية النية

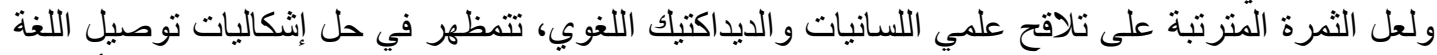

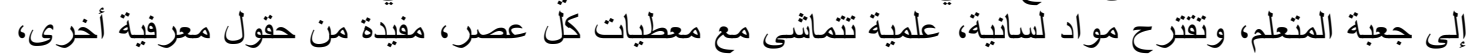

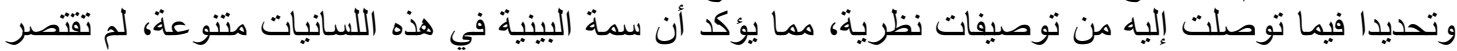

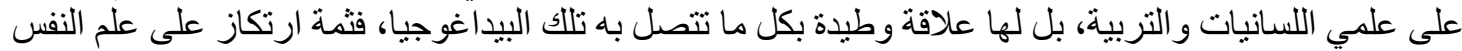

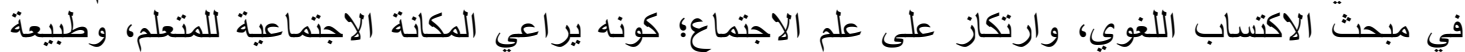

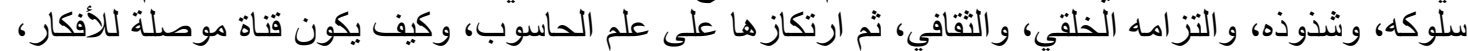

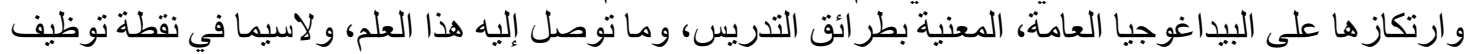

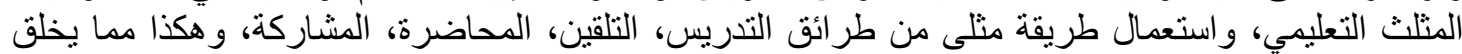

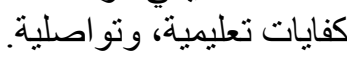

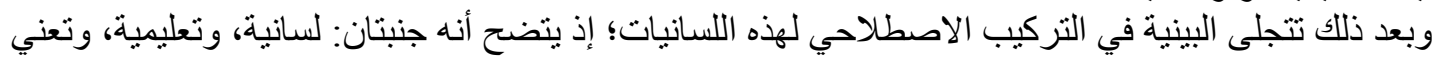

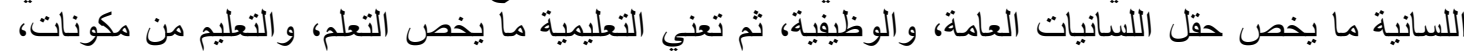

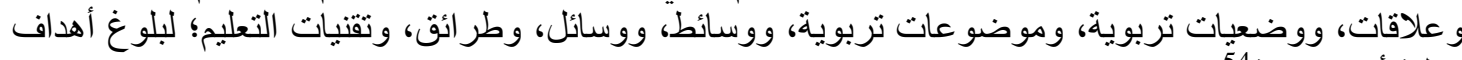
عقلية أو وجدانية

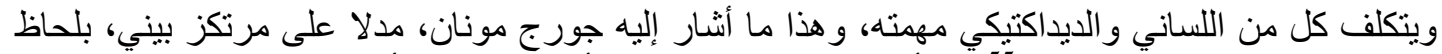

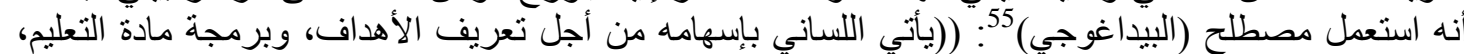

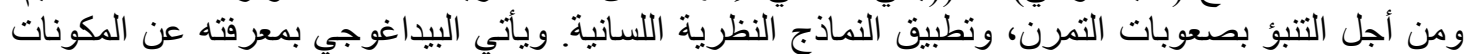

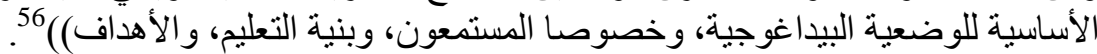

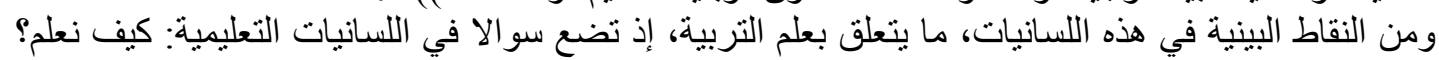

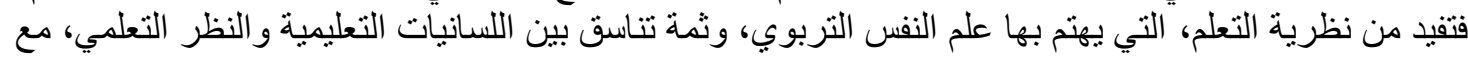

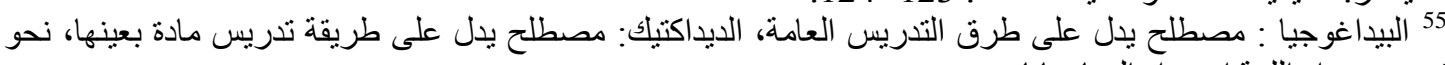




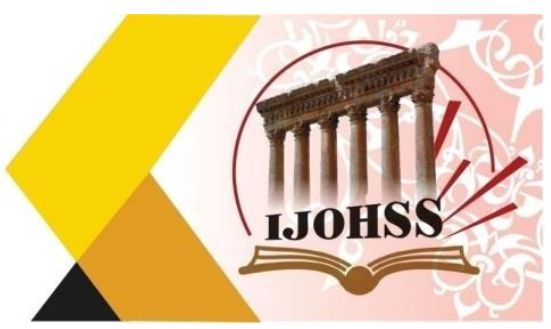

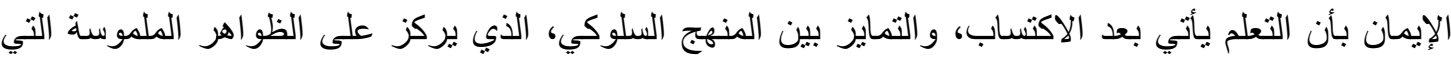

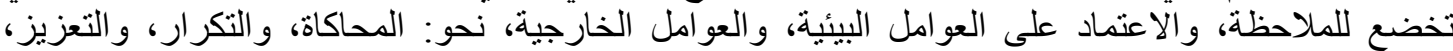

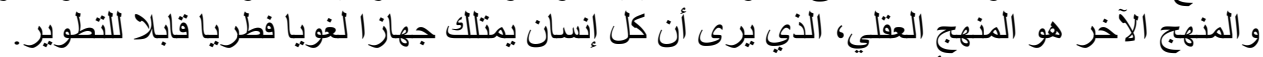

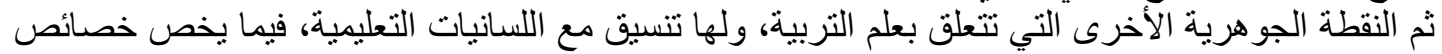

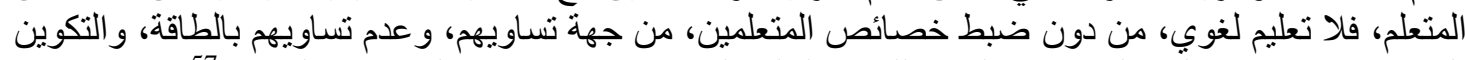

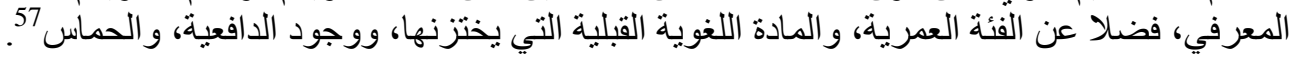

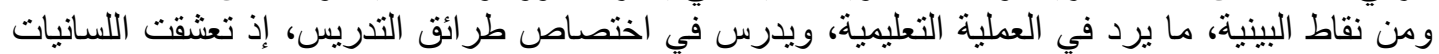

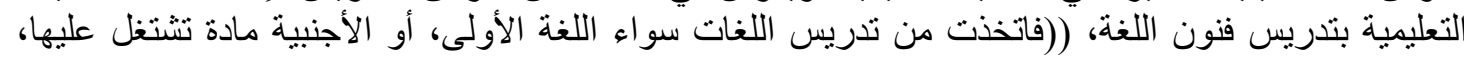
و إنثكاليات تتعلق كل واحدة منها بمكون من مكونات العملية التعليمية: المعلم، المتعلم، الأهداف، المحتية المحتوى،

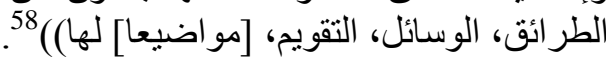

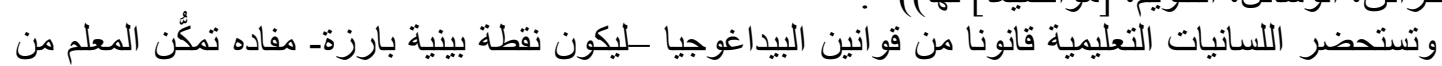

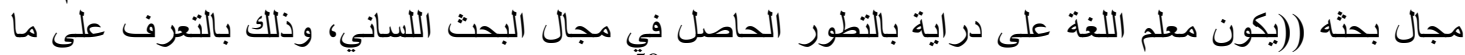

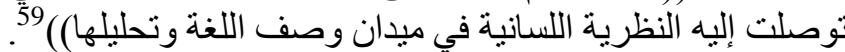

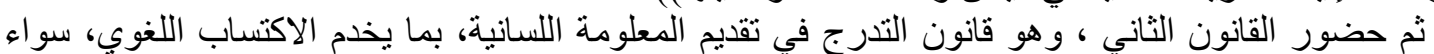

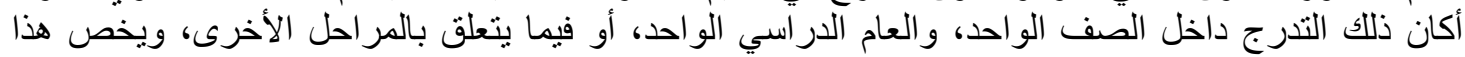

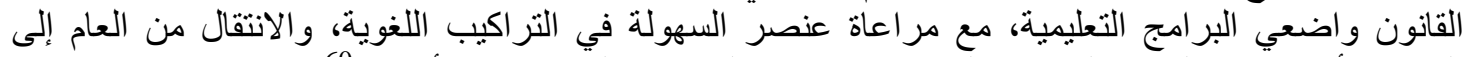

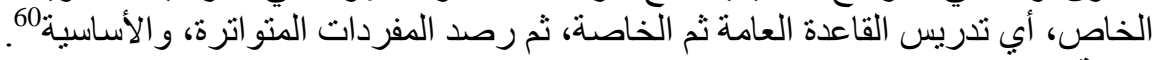
خاتمة البحث

بعدما تم دفع الترادف بينها وبين علم اللغة التطبيقي، كون أن هذه التسمية شاعت في الأوساط العلمية لحداثة

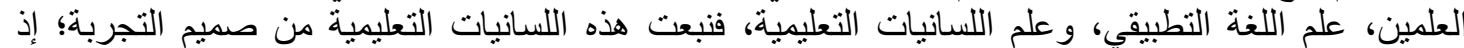

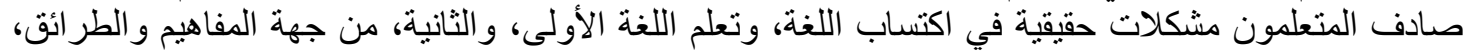

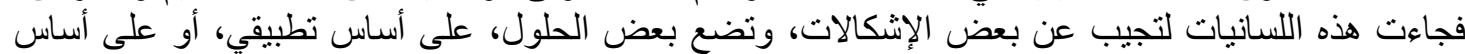

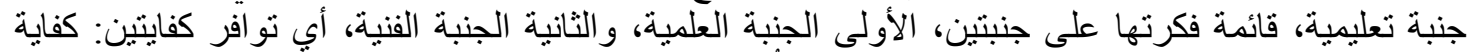

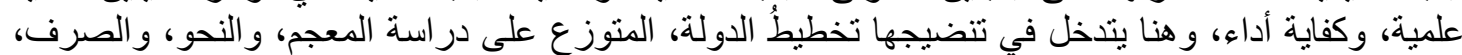

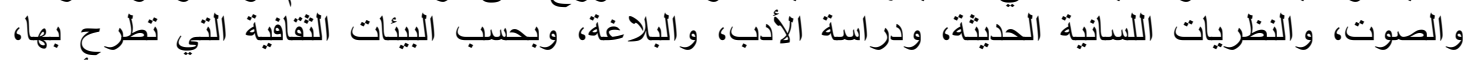

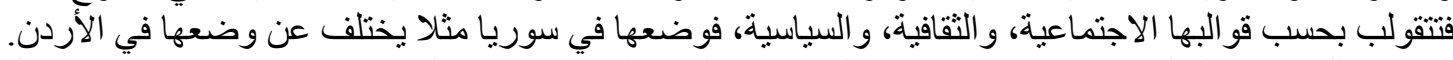

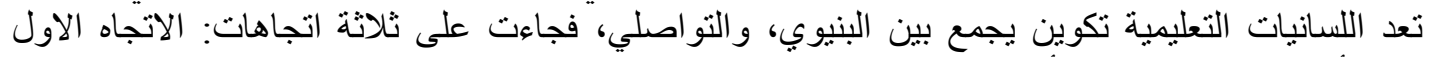

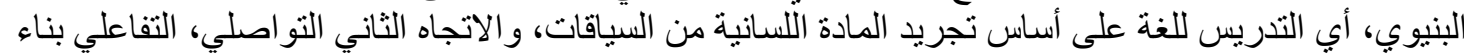

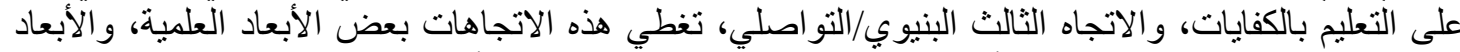

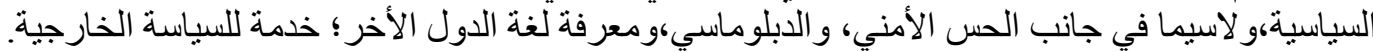

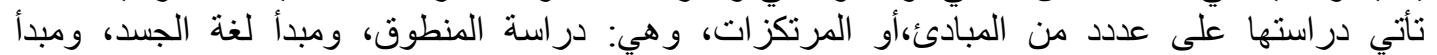

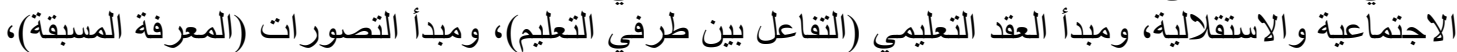

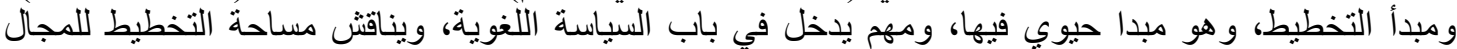

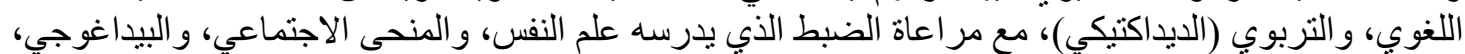
فنكون أمام لسانيات تعتد باللغة، وبتحليل الخيل الخطاب، وبالتداولية.

57 ينظر: علم اللغة النطبيقي وتعليم العربية: 27- 28.

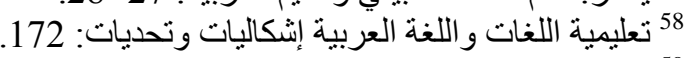

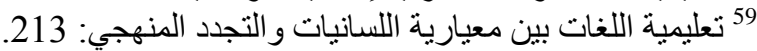

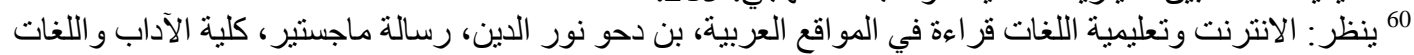




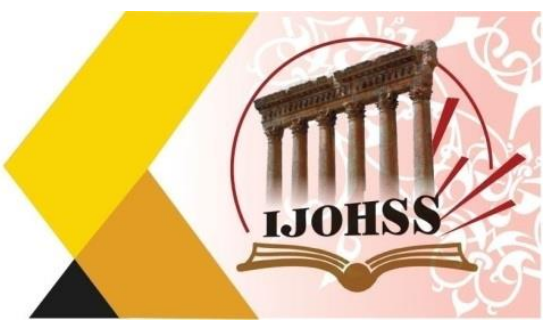

مصادر البحث

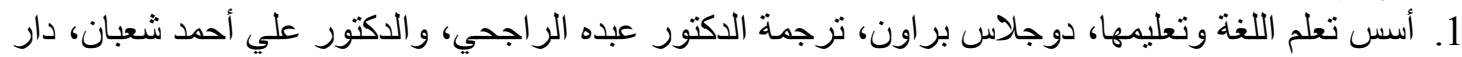

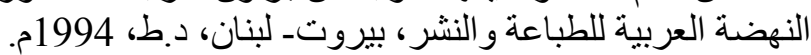

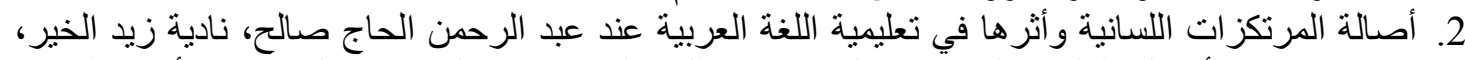

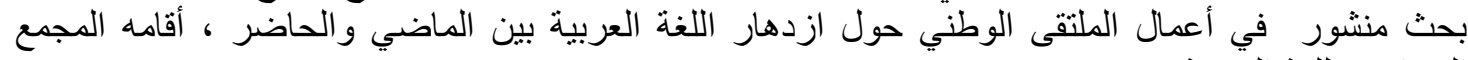

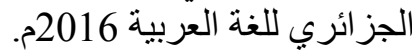
3. الانترنت وتعليمية اللغات قر اءة في المو اقع العربية، بن دحو نور الدين، رسالة ماجستير، كلية الآداب و اللغات

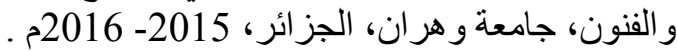
4. البحث العلمي ودوره في جودة التعليم، أبو بكر العز اوي، بحث منشور في المجلة المغربية للتربية، العدد 8، 2017

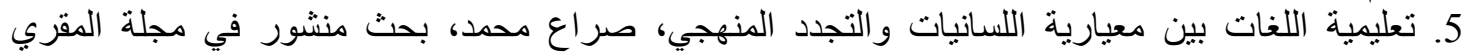

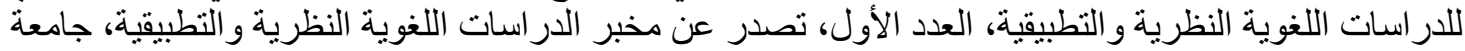
محمد بو ضياف، الجز ائر. 6. تعليمية اللغات و اللغة العربية: إثكاليات وتحديات، لطيفة الهباثي، بحث منشور في مجلة التو اصل في اللغات

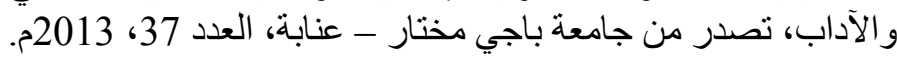

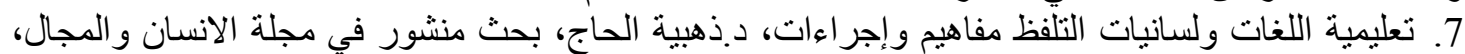

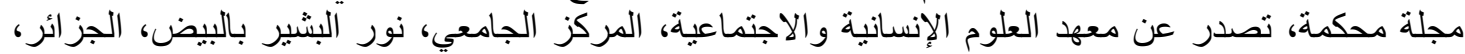

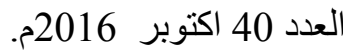

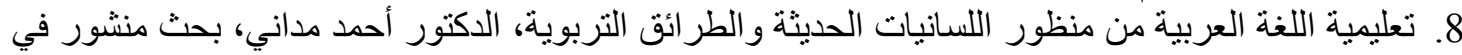

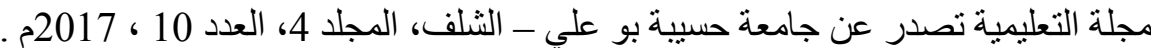

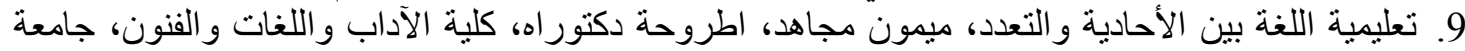

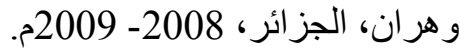

10.

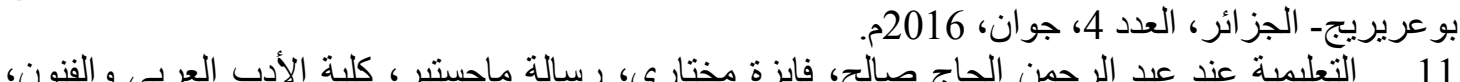

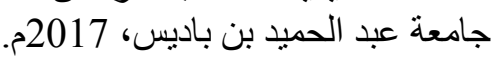
12. امعة توظيف اللسانيات في تعليم اللغات، الدكتور رضا الطيب الكثو، مجمع اللغة العربية على الثبكة العالمية،

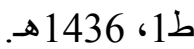
13. دراسات في اللسانبات التطبيقية حقل نعليمية اللغات، الدكتور أحمد حساني، ط1، ديوان المطبوعات

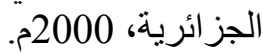
14. علاقة التداولية بالتدريس مسعى لتبني التداولية التعليمية، خالد حوير الثمس، بحث منشور في مجلة اداب ذي قار، العدد الخاص بالمؤتمر العلمي الدولي الخامس 2012 2012. 15. . علم اللغة التطبيقي وتعليم العربية، د. عبده الرئي اجحي، د.ط، دار المعرفة الجامعية، الاسكندرية - مصر،

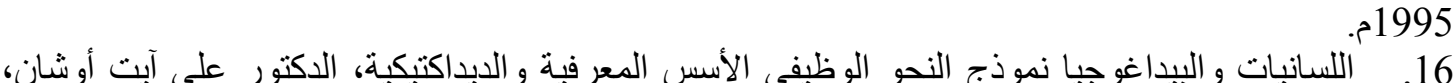

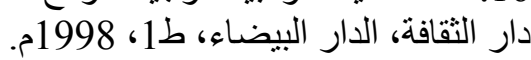
17. اللسانيات و التربية المقاربة بالكفايات و التندريس بالمفاهيم، علي ايت اوشان، ط1، دار أبي رقراق للطباعة

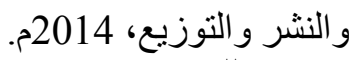

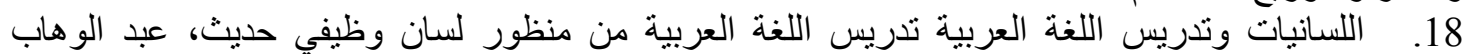
صديقي، بحث منشور في مجلة الدراسات اللغوية والأدبية، تصدر عن الجامعة الإسلامية، في ماليزيا، العدد الثاني، 2011م. 19.

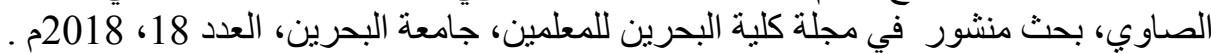




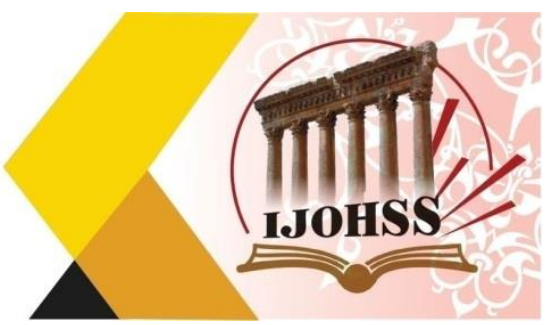

20. مباحث تأسيسية في اللسانيات، الدكتور عبد السلام المسدي، مؤسسات عبد الكريم بن عبد اله للنشر و التوزيع، تونس، 1997م.

21. معجم اللسانيات، بإنشر اف جورج مونان، ترجمة الدكتور جمال الحضري، المؤسسة الجامعية للار اسات

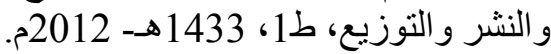

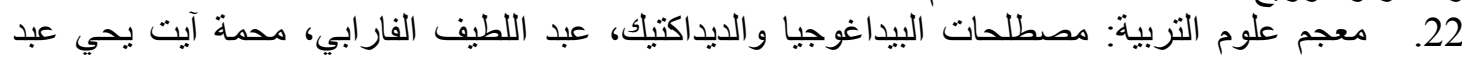
العزيز الغرضاف، عبد الكريم غريب، سلسلة علوم التربية، التئة 2009- 2010 2010م.

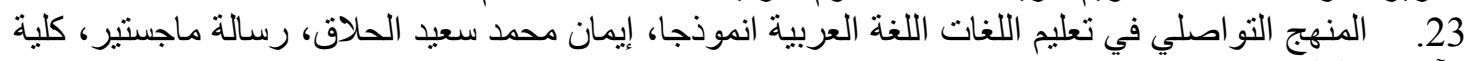

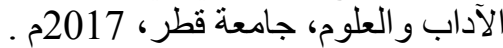

24. و اقع التخطيط اللغوي للخطاب التعليمي دراسة وصفية في كتب تعليم اللغة العربية للناطقين بغيرها في الوطن العربي، الدكتور خالد عبد الكريم بسندي، دار كنوز المعرفة، عمانـ الأردن، ط1، 1441 هــ 2020م. 